\title{
ESTUDIO TECNO-ECONÓMICO DE LA INDUSTRIA LÍTICA DE CERRO CASTILLO (PROVINCIA DE ÚLTIMA ESPERANZA, CHILE).
}

\author{
MATHIEU LANGLAIS* Y FLAVIA MORELLO**
}

\begin{abstract}
RESUMEN
El presente estudio tecno-económico de los materiales líticos recuperados en el sitio Cerro Castillo 1, provincia de Última Esperanza - Chile, entrega nuevos antecedentes sobre los grupos cazadores terrestres que vivieron en la zona hacia aproximadamente 4.500 años AP. El conjunto permite caracterizar algunos esquemas de desbaste, con énfasis en un sistema técnico basado en la gestión de núcleos con volúmenes bifaciales destinados a producir lascas, las que luego son formatizadas por retoque en raederas, raspadores y otros instrumentos. También se registran otras cadenas operatorias menos representadas, como son un proyecto laminar y el uso de métodos de desbaste sobre yunque. Destacamos la débil presencia de series orientadas a la manufactura de bifaces o métodos de façonnage.
\end{abstract}

PALABRAS CLAVES: Tecnología, economía, lítico, Patagonia.

\section{TECHNO-ECONOMIC STUDY OF CERRO CASTILLO LITHIC INDUSTRY (PROVINCIA ÚLTIMA ESPERANZA, CHILE).}

\section{ABSTRACT}

The present techno-economic study of lithic materials recovered in Cerro Castillo 1 site, provincia de Última Esperanza - Chile, delivers new precedents about the terrestrial hunter groups that lived in the area approximately 4.500 years BP. The set allows characterizing reduction schemes that emphasize technical systems based on the management of bifacial volumes in flake core production, which are then transformed by retouch in sidescrapers, endscrapers and other instruments. Other less represented operative chains are also recorded, as a blade project and the use of percussion over anvil methods. The weak presence of series orientated to the manufacture of bifacial artifacts or façonnage methods is emphasized.

KEYWORDS: Technology, economy, lithic, Patagonia.

* Laboratoires TRACES (UMR 5608, Université de Toulouse) et SERP (Université de Barcelone), matlang1@wanadoo.fr

* Centro de Estudios del Hombre Austral, Instituto de Patagonia, Universidad de Magallanes y Centro de Estudios del Cuaternario - CEQUA. Flavia.morello@umag.cl. 


\section{INTRODUCCIÓN}

El sitio arqueológico Cerro Castillo es un abrigo rocoso ubicado cerca del poblado homónimo, en Patagonia austral (Chile), provincia de Última Esperanza. El alero se abre en el seno de un cerro de conglomerados del Oligoceno, en una zona en donde confluyen varios ríos conformando un nódulo de comunicación y movilidad norte-sur tanto como hacia el sector estepárico, al oriente.

El presente estudio aborda la totalidad de los materiales líticos del yacimiento con el objeto de caracterizar los comportamientos tecno-económicos de los cazadores recolectores holocénicos que ocuparon reiteradamente este abrigo. Los restos corresponden a materiales recuperados en dos excavaciones de sondeo (San Román y Morello 2003; Legoupil 2009), las que suman una superficie de $2,5 \mathrm{~m}^{2}$ excavados, con una profundidad máxima de 2 metros.

La presentación general de los trabajos realizados en este yacimiento del Holoceno medio-tardío se encuentran en Legoupil (2009, en este volumen) y San Román y Morello (2003). Además, se realizaron estudios especializados de geoarqueología y antracología (Bertran 2009, Solari 2009, en este volumen).

El conjunto lítico estudiado incluye 10650 piezas que se reparten en diferentes porciones de la secuencia, concentrándose en las unidades sedimentarias III y IV (83\% del total) definidas por Bertran (2009, en este volumen) - Fig. 1. Esta concentración esta ubicada inmediatamente sobre un lente de fogón fechado en $4.580 \pm 80$ años $\mathrm{AP}$ (San Román y Morello 2003) y, dada su apretada dispersión estratigráfica y la homogeneidad del conjunto artefactual, se abordó la colección como una unidad de análisis.

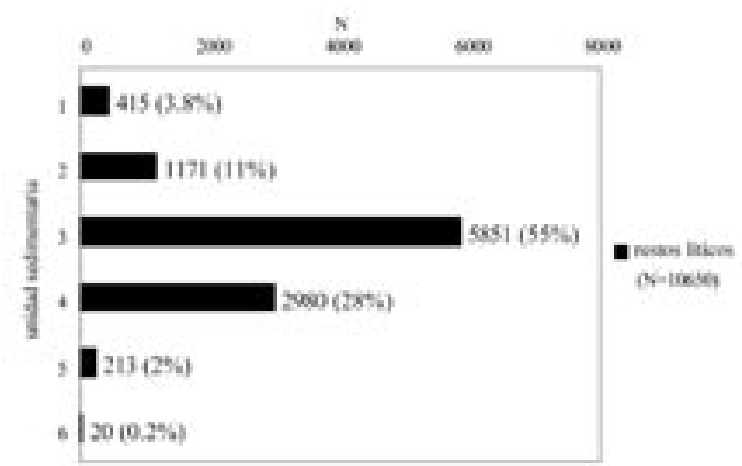

Fig. 1. Distribución de restos líticos por unidad sedimentaria.
Se aplicaron los conceptos clásicos de la tecnología lítica, que fueron definidos para el Paleolítico europeo (Geneste1985, Boëda 1986, 1994, Bourguignon 1997) y los utilizados en Patagonia por N. Pigeot y V. Schidlowsky (cf. infra). La metodología de análisis lítico consideró, primero, la segregación por tipos generales de artefacto y materia prima y, segundo, la reconstrucción de las cadenas operatorias de producción y transformación representadas mediante la clasificación de los restos según variables tecnológicas y morfofuncionales. Además, como procedimiento general se hicieron múltiples intentos de remontaje de material, los que resultaron infructuosos debido, probablemente, a la escasa superficie excavada y la homogeneidad macroscópica de las materias primas, predominando la lutita.

A continuación se presentan los resultados del análisis, una discusión de la importancia de los aspectos tecno-económicos, su comparación con otros conjuntos líticos de Patagonia y las conclusiones del presente estudio.

\section{RESULTADOS}

El análisis general de los tipos de desecho representados en el conjunto indica que hay un predominio de la fracción fina, esquirlas y astillas, que representan el $78 \%$ de los restos. Los otros artefactos $(\mathrm{N}=2339)$ están dominados por lascas $(\mathrm{N}=1250)$ y fragmentos sin talón ( $N=1020)$. Podemos notar, igualmente, la presencia de soportes de tendencia alargada $(\mathrm{N}=26)$ y algunas láminas $(\mathrm{N}=25)$. También se identificaron guijarros $(\mathrm{N}=13)$ y fragmentos térmicos $(\mathrm{N}=5)$, de dudoso origen antrópico.

Luego, nos hemos focalizado en los conjuntos correspondientes a las unidades estratigráficas II a $\mathrm{V}$, es decir 10215 piezas $(\mathrm{N}=2283$ artefactos sin considerar las esquirlas menores) ${ }^{1}$.

\section{MATERIAS PRIMAS}

Las materias primas líticas fueron identificadas según criterios macroscópicos y provienen, en su mayoría, de materiales acarreados por los glaciares y principalmente guijarros de depósitos morénicos, disponibles en el medio ambiente local.

1 No consideramos el material del US 1 en este estudio por tratarse de restos disturbados por el pisoteo de ovejas y mezclado con excremento. 
Tabla 1. Materias primas líticas (MP) por unidad sedimentaria (US).

\begin{tabular}{|l|r|r|r|r|r|r|r|r|r|}
\hline \multicolumn{1}{|c|}{ MP/US } & \multicolumn{1}{c|}{ II } & \multicolumn{1}{c|}{ III } & \multicolumn{1}{c|}{$\%$} & \multicolumn{1}{c|}{ IV } & \multicolumn{1}{c|}{$\%$} & V & \multicolumn{1}{c|}{ Total } \\
\hline Lutita & 711 & 85,05 & 4796 & 77,53 & 2420 & 85,36 & 301 & 84,08 & 8228 \\
\hline Silex & 47 & 5,62 & 499 & 8,07 & 63 & 2,22 & 10 & 2,79 & 619 \\
\hline Riolita & 31 & 3,71 & 269 & 4,35 & 91 & 3,21 & 2 & 0,56 & 393 \\
\hline Calcedonia & 10 & 1,20 & 149 & 2,41 & 58 & 2,05 & 16 & 4,47 & 233 \\
\hline Obsidiana gris veteada & 1 & 0,12 & 5 & 0,08 & 16 & 0,56 & 10 & 2,79 & 32 \\
\hline Obsidiana verde o negra indet. & 1 & 0,12 & & & 6 & 0,21 & 9 & 2,51 & 16 \\
\hline Jaspe & 1 & 0,12 & 2 & 0,03 & 1 & 0,04 & 1 & 0,28 & 5 \\
\hline Obsidiana verde & & & & & 5 & 0,18 & & & 5 \\
\hline Arenisca & & & 2 & 0,03 & & & & & 2 \\
\hline Obsidiana negra & & & & & & & 1 & 0,28 & 1 \\
\hline \multicolumn{1}{|c|}{ Total } & 836 & 100,00 & 6186 & 100,00 & 2835 & 100,00 & 358 & 100,00 & 10215 \\
\hline Indeterminadas & 34 & 4,07 & 464 & 7,50 & 175 & 6,17 & 8 & 2,23 & 681 \\
\hline
\end{tabular}

En el conjunto, la lutita silicificada es mayoritaria, representando el $86 \%$ de los vestigios líticos determinados (Tabla 1). El segundo grupo en términos cuantitativos (6,6\% del total) es un conjunto diverso de materiales indeterminados. Además de la fuerte predominancia de las lutitas, podemos destacar que el espectro litológico de las unidades estratigráficas II y III es muy semejante y se distingue de las materias primas de las unidades IV y $\mathrm{V}$, que son proporcionalmente más ricas en artefactos de obsidiana (Fig. 2).

El análisis de las materias primas permite relevar ciertas elecciones económicas en la colección:

- Las lutitas constituyen el pilar central de la economía de los ocupantes de Cerro Castillo, en términos de desbaste y fabricación de instrumentos. Se distinguen varias cadenas operatorias ( $c f$. infra). Destacamos, por el momento, que la lutita es explotada para producir lascas, láminas y formatizar o façonner "masas" bifacialmente (cf. Schidlowsky 2001).

- Las rocas silíceas están representadas principalmente bajo la forma de esquirlas y, notablemente, de desechos de façonnage o formatización bifacial. Entre las piezas encontramos pequeños pedazos y algunos soportes de dimensión más grande (50-60 mm). Este material está poco representado entre los instrumentos, y posiblemente fueron introducidos y no manufacturados en el alero, siendo transportados al abandonar el sitio.

- Las riolitas están representadas por lascas extendidas de un tipo de desbaste invasivo (cf. infra) o cortas, y marginalmente entre los instrumentos.

- Las calcedonias se registran principalmente como desechos de talla y de instrumentos, entre los cuales se anota la presencia de raspadores y de piezas de retoque lateral.
- Se distinguieron 3 tipos de obsidiana: las variedades verdes y negras, que están presentes en cantidades muy marginales, bajo la forma de microdesechos, y de un pedazo con restos de corteza, en el caso de la obsidiana negra. La obsidiana gris veteada es el tercer tipo representado y es la más abundante, incluyendo esquirlas de formatización bifacial y dos pequeñas puntas de proyectil, de morfología triangular, realizadas a presión (cf. infra). La variedad gris se distingue bastante fácilmente por su textura bandeada y semi traslúcida, pero en piezas de tamaño reducido, las variedades negras y verdes no permiten esta precisión.

- Entre las otras rocas, algunos guijarros de cuarcita y de rocas indeterminadas son utilizados como macro instrumentos o yunques (San Román y Morello 2003).

- Se observa un caso de desechos de talla y raspadores en jaspe rojo. Destacamos que una parte no despreciable de estas piezas presentan los estigmas característicos de la percusión apoyada o sobre yunque (cf. Infra), comportamiento técnico documentado en otras regiones de Fuego-Patagonia (Morello 2005) y utilizados con el fin de rentabilizar al máximo ciertos materiales de grano fino y nódulos de módulo pequeño.

\section{INFORMACIÓN TIPOLÓGICA}

Los instrumentos líticos representan el 9\% del conjunto de los vestigios (sin considerar las esquirlas), es decir 209 piezas. Mientras la inmensa mayoría de los utensilios fueron realizados sobre lutita, los raspadores muestran una diversidad más grande 
Tabla 2. Tipos de instrumentos.

\begin{tabular}{|c|c|c|}
\hline A & Instrumento de retoques laterales & $\mathrm{N}=65$ \\
\hline B & Raedera & $\mathrm{N}=57$ \\
\hline C & Raspador & $\mathrm{N}=38$ \\
\hline D & Cuchillo & $\mathrm{N}=14$ \\
\hline E & Pieza con troncadura & $\mathrm{N}=10$ \\
\hline F & Macro-util & $\mathrm{N}=6$ \\
\hline G & Bifaz & $\mathrm{N}=6$ \\
\hline H & Bec & $\mathrm{N}=5$ \\
\hline I & Denticulado & $\mathrm{N}=4$ \\
\hline J & Muesca & $\mathrm{N}=2$ \\
\hline K & Punta bifacial & $\mathrm{N}=2$ \\
\hline & Total & 209 \\
\hline
\end{tabular}

de materias primas. Del punto de vista tipológico se han distinguido 11 categorías de instrumentos, entre los cuales dominan los artefactos con retoques laterales, seguidos por las raederas, los raspadores y los cuchillos (Tabla 2).

Con relación a los soportes, los instrumentos fueron realizados preferentemente sobre lascas y fragmentos (Tabla 3). Se observa que las láminas y los soportes alargados fueron destinados mayorita-

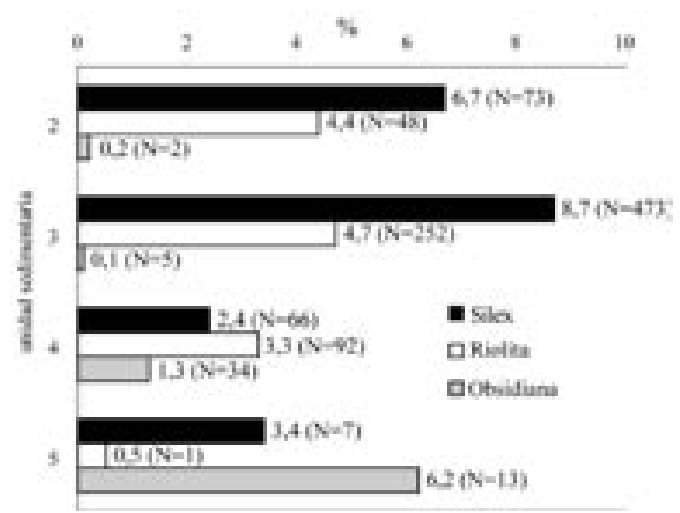

Fig. 2. Distribución de rocas silíceas, riolitas y obsidianas por unidad sedimentaria.

riamente a la manufactura de cuchillos y raspadores. Sería interesante evaluar en el futuro la razón de esta elección, que puede asociarse en el caso de los raspadores (instrumento de extremidad) a la necesidad de enmangado o preferencias de reavivado y manutención, o bien, para los cuchillos (instrumento lateral), a una selección óptima para la longitud del filo. Al contrario, las raederas fueron realizadas sobre lascas de espesor bastante constante (cf. infra).

Tabla 3. Soportes de instrumentos por unidad sedimentaria (US).

\begin{tabular}{|c|c|c|c|c|c|c|c|c|c|c|c|c|}
\hline Instrumentos* & A & $\mathrm{B}$ & $\mathrm{C}$ & $\mathrm{D}$ & $E$ & $\mathrm{~F}$ & G & $\mathrm{H}$ & I & $\mathrm{J}$ & $\mathrm{K}$ & Total \\
\hline \multicolumn{13}{|c|}{ soportes US II } \\
\hline fragmento & 3 & 4 & 4 & & & & 1 & & & & & 12 \\
\hline lasca & 4 & 2 & 1 & & & & & & & & & 7 \\
\hline lámina & & & & 1 & & & & & & & & 1 \\
\hline Sub-Total & 7 & 6 & 5 & 1 & 0 & 0 & 1 & 0 & 0 & 0 & 0 & 20 \\
\hline \multicolumn{13}{|c|}{ soportes US III } \\
\hline fragmento & 24 & 12 & 11 & 1 & 5 & & 4 & 3 & 3 & 2 & & 65 \\
\hline lasca & 12 & 6 & 7 & 1 & 3 & & & 2 & & & & 31 \\
\hline guijarro & 1 & & & & & 3 & & & & & & 4 \\
\hline lámina & 2 & & 2 & 1 & & & & & & & & 5 \\
\hline Sub-Total & 39 & 18 & 20 & 3 & 8 & 3 & 4 & 5 & 3 & 2 & 0 & 105 \\
\hline \multicolumn{13}{|c|}{ soportes US IV } \\
\hline fragmento & 12 & 20 & 8 & 3 & & & & & & & 2 & 45 \\
\hline lasca & 7 & 13 & 3 & 1 & 2 & & & & 1 & & & 27 \\
\hline lámina & & & 1 & 5 & & & & & & & & 6 \\
\hline guijarro & & & & & & 2 & & & & & & 2 \\
\hline Sub-Total & 19 & 33 & 12 & 9 & 2 & 2 & 0 & 0 & 1 & 0 & 2 & 80 \\
\hline \multicolumn{13}{|c|}{ soportes US V } \\
\hline fragmento & & & 1 & & & & 1 & & & & & 2 \\
\hline lasca & & & & 1 & & & & & & & & 1 \\
\hline guijarro & & & & & & 1 & & & & & & 1 \\
\hline Sub-Total & 0 & 0 & 0 & 1 & 0 & 1 & 1 & 0 & 0 & 0 & 0 & 4 \\
\hline TOTAL & 65 & 57 & 37 & 14 & 10 & 6 & 6 & 5 & 4 & 2 & 2 & 209 \\
\hline
\end{tabular}

* Códigos de instrumentos según Tabla 2. 
Las piezas bifaciales fueron manufacturadas tradicionalmente, ya sea a partir de la reducción de masas centrales, o a partir de fragmentos. No obstante, la formatización bifacial ha abarcado gran parte de ambas caras, por lo que es difícil caracterizar con certeza el soporte inicial (masa, lasca gruesa o fragmento). Es así como los soportes de piezas bifaciales han sido incluidos, por defecto, en el conjunto de fragmentos.

Aparte de un único artefacto bifacial que incluye una forma obtenida con esmero y utilizando percusión blanda (Fig. 3), hay varias piezas que podrían ser preformas realizadas con percusión dura y otras corresponder a núcleos (Fig. 4).

\section{Raederas}

Esta categoría es confeccionada principalmente a partir de fragmentos o lascas extendidas y de dorso natural, proviniendo de un desbaste de tipo Levallois (cf. infra). Entre las piezas enteras $(\mathrm{N}=31$, Fig. 5 № 4-7), distinguimos raederas de retoque marginal simple $(\mathrm{N}=17)$ o marginal doble convergente $(\mathrm{N}=14$, Fig. $\left.5 n^{\circ} 1-3,8,9\right)$. Varias piezas presentan bordes retocados con filos de ángulos variables, que comprenden una o varias líneas de retoque- reavivado (Fig. 5). Los ángulos de los filos del borde activo son relativamente abiertos y varían entre $55-60^{\circ}$. La sucesión de líneas de retoque se genera por retoque directo, muy raramente inverso, conformando un borde con retoque escalerado.

La relativamente importante apertura de los ángulos del borde en las raederas puede relacionarse con el evidente agotamiento del filo retocado, que progresivamente va perdiendo incidencia en el reavivado del ángulo según retrocede hacia el interior de la pieza. Entonces, hay una relación entre ángulo y cantidad de líneas de retoque-reavivado; las raederas que presentan un ángulo de $40-50^{\circ}$ llevan un retoque marginal no escalerado y vice versa, a mayor ángulo, mas probable es la presencia de retoque escalerado. En otros términos, la disminución de la incidencia del ángulo del filo se correlaciona con el carácter escalariforme del borde y con el número total de líneas de retoque y reavivado del borde. En algunas raederas, y también entre los desechos, fue posible identificar un procedimiento técnico relacionado con este agotamiento provisorio del borde activo de las raederas. Sobre ciertas piezas, un golpe en la por-

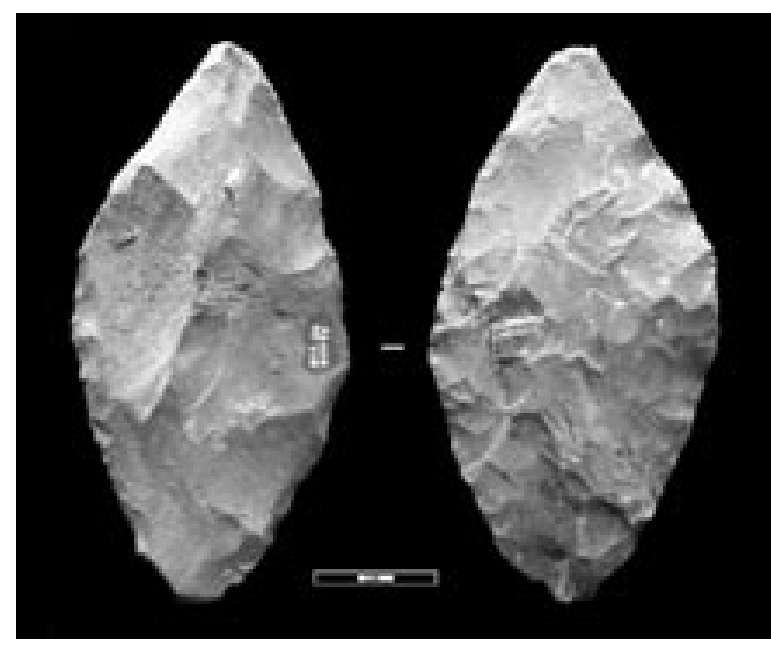

Fig. 3. Imagen de pieza bifacial (fotografía M. Langlais).

ción lateral (coup de tranchet latéral, Bourguignon 1999) permitió recobrar una cierta incidencia del borde, adelgazando la zona mesial o la parte más gruesa de la pieza, con el fin de afinar el ángulo del borde o reavivarlo por retoque de una manera más efectiva (Figs. $5 \mathrm{~N}^{\circ} 4$ y 6). Con respeto al punto de contacto de estas extracciones de mantenimiento del borde activo de la pieza, frecuentemente los talones y los bulbos son retomados por extracciones uni o bifaciales destinados a adelgazar la base. En el caso de las raederas dobles convergentes, es difícil precisar si ambos bordes son formatizados a la vez, para una utilización alternante como raederas simples, o, si son confeccionados sucesivamente, cuando el primer borde ha sido agotado.

En resumen, podemos notar una gestión planificada y programada de las raederas a lo largo de su utilización:

- Un retoque escamoso escaleriforme de fuerte amplitud que permite prolongar la eficacia del filo, a pesar del retroceso del retoque en el espesor de la pieza;

- Las primeras líneas del borde son de un retoque rasante, de fuerte incidencia, que permite anticipar los reavivados futuros;

- Hay procedimientos de reavivado del filo, como los golpes en la porción lateral (coup de tranchet latéral); y

- El adelgazamiento de la base, probablemente destinado a la manutención del artefacto.

En términos estratigráficos podemos observar que los artefactos enteros son proporcionalmente 


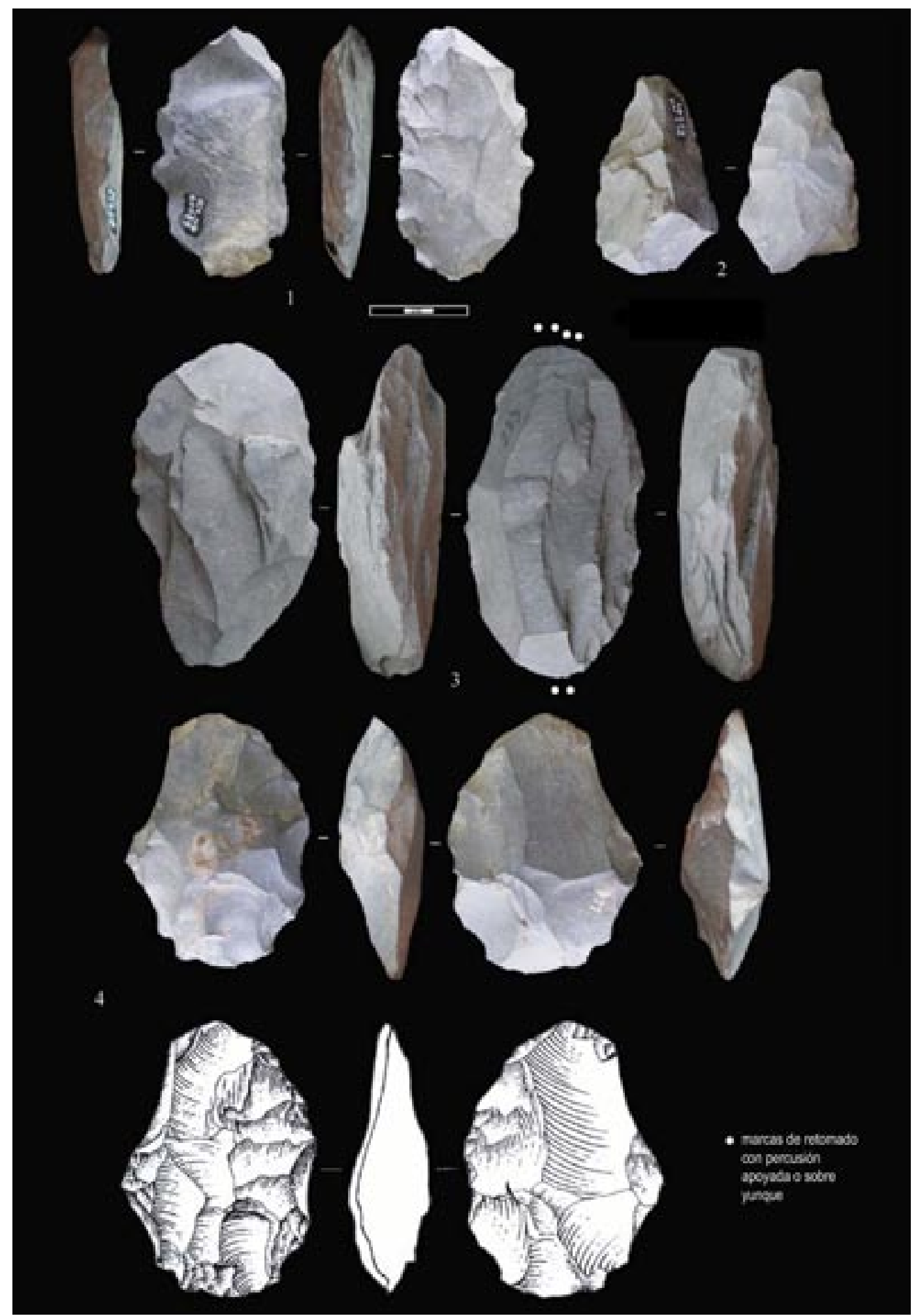

Fig. 4. Ejemplos de piezas bifaciales: ¿preformas o núcleos de lascas? (fotografías M. Langlais, dibujos D. Molez). 


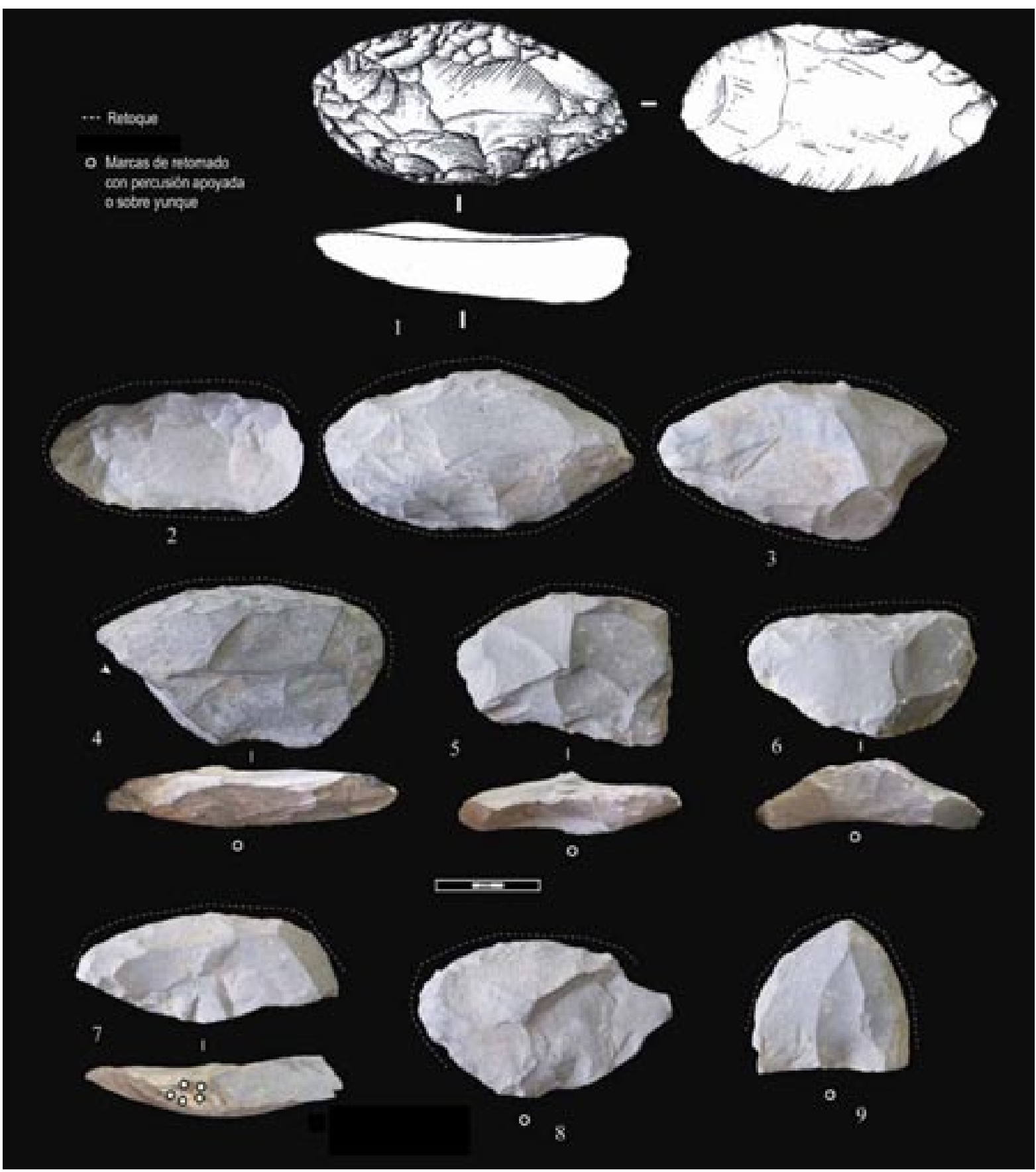

Fig. 5. Raederas de Cerro Castillo (fotografías de M. Langlais, dibujo D. Molez).

más numerosos en la unidad IV que en la capa III. Pero se han ejecutado las mismas técnicas a lo largo de toda la secuencia, mostrando conservación en las tradiciones y comportamientos tecno-económicos.

\section{Raspadores}

Desde un punto de vista tipológico, pudimos identificar raspadores simples o dobles, unguiformes y ojivales (Fig. 8). Las dimensiones generales de estas 


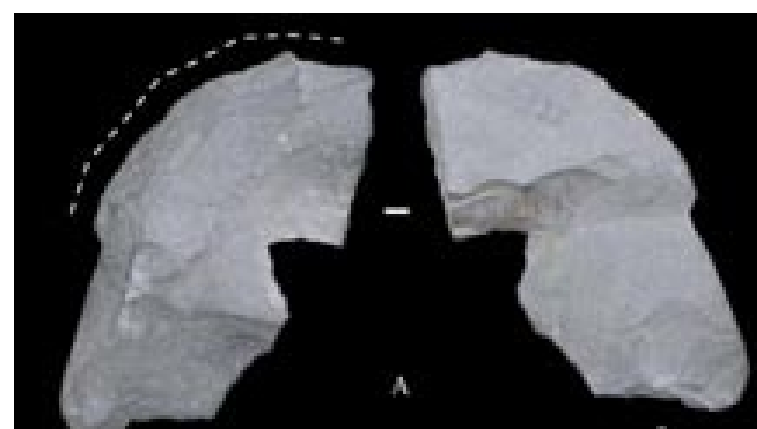

c
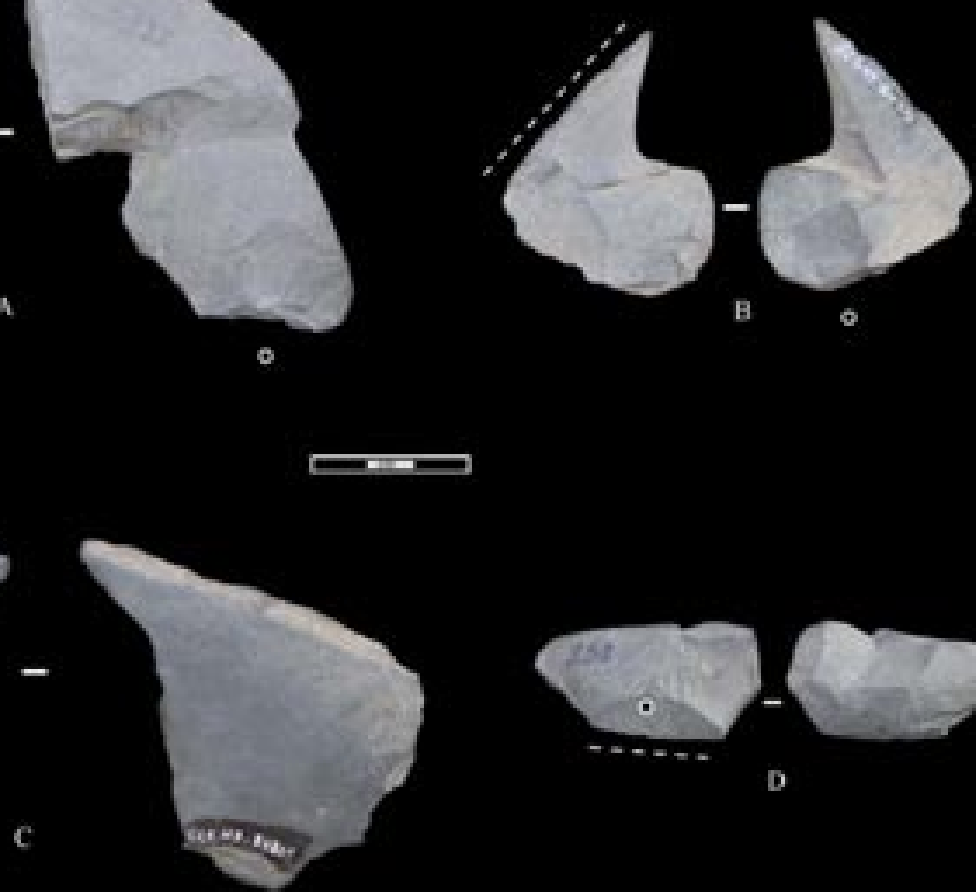

E

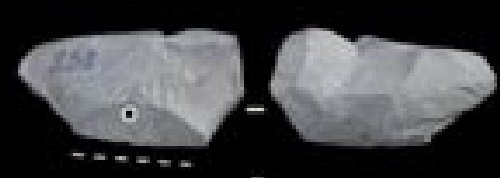

D

o

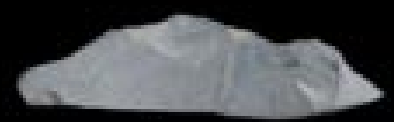

I
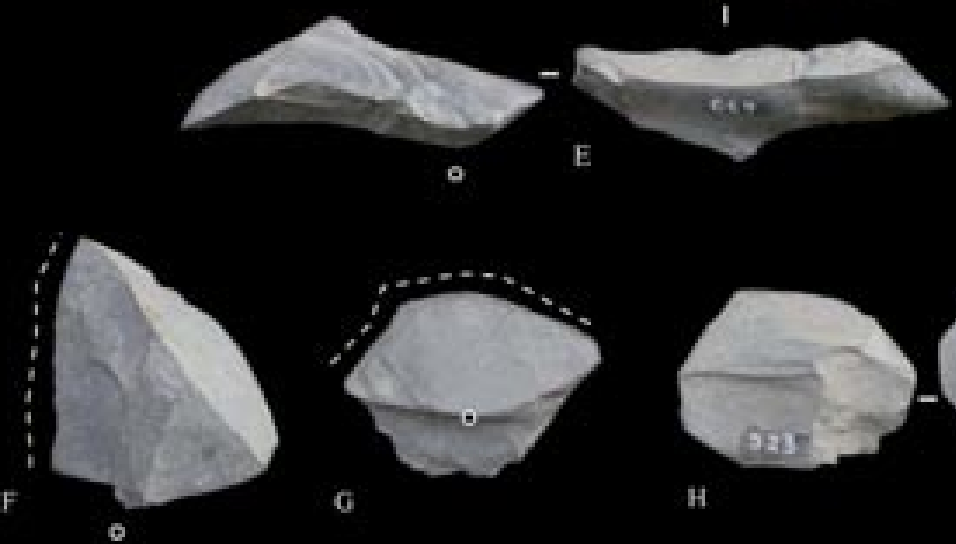

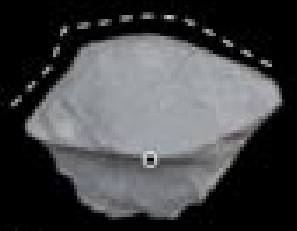

c.

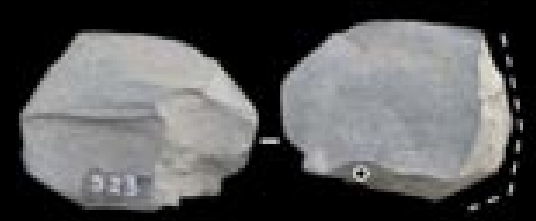

14

Fig. 6. Ejemplos de lascas de reavivado de raederas: A-C piezas sobrepasadas, D y F-H lascas de golpes en porción lateral (coup de tranchet latéral), E: lasca de adelgazamiento basal (fotografías M. Langlais).

piezas son menores que las raederas (Fig. 7); fueron elaboradas en materiales silíceos y frecuentemente confeccionados a partir de soportes desbastados sobre yunque o percusión apoyada. Sólo un ejemplar fue realizado sobre lámina. También se registra otra pieza sobre una lasca delgada que parece presentar un sector pulido por uso sobre la cara superior, ¿rastros de enmangado o de manutención? (A. Prieto, obs. pers.).

En comparación con las raederas, los frentes de los raspadores presentan una incidencia más 


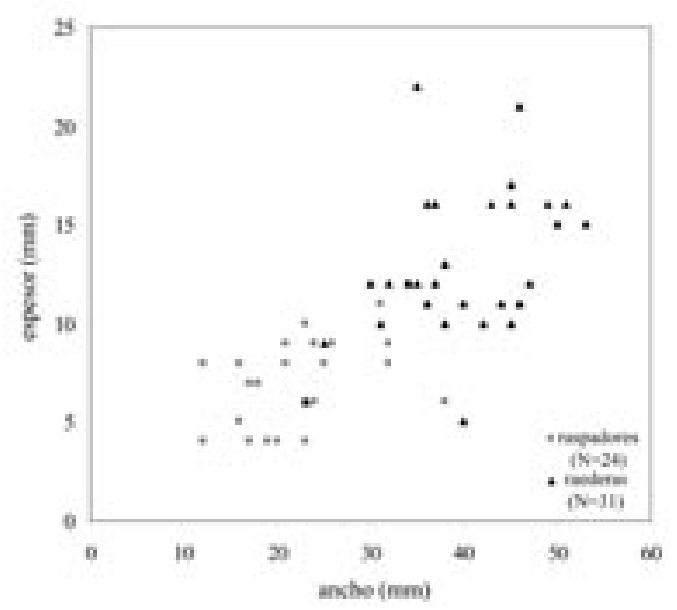

Fig. 7. Gráfico de comparación de las dimensiones de raederas y raspadores. débil del borde del filo, con ángulos frecuentemente superiores a $60^{\circ}$. Esta diferencia puede relacionarse con la sinergia, dirección, inclinación y gesto, al momento de utilización $\mathrm{y} / \mathrm{o}$ a las distintas funciones de estos instrumentos.

Cuchillos

Estos instrumentos fueron generalmente realizados sobre soportes alargados (lascas o láminas), las piezas analizadas están provistas de un retoque rasante, directo, uni o bimarginal. Se distinguen de las raederas por la delineación más rectilínea de uno o varios bordes retocados (cf. Schidlowsky 2001). Además, el retoque presenta una incidencia más rasante, agudo y menos profundo que las raederas. En esta categoría se

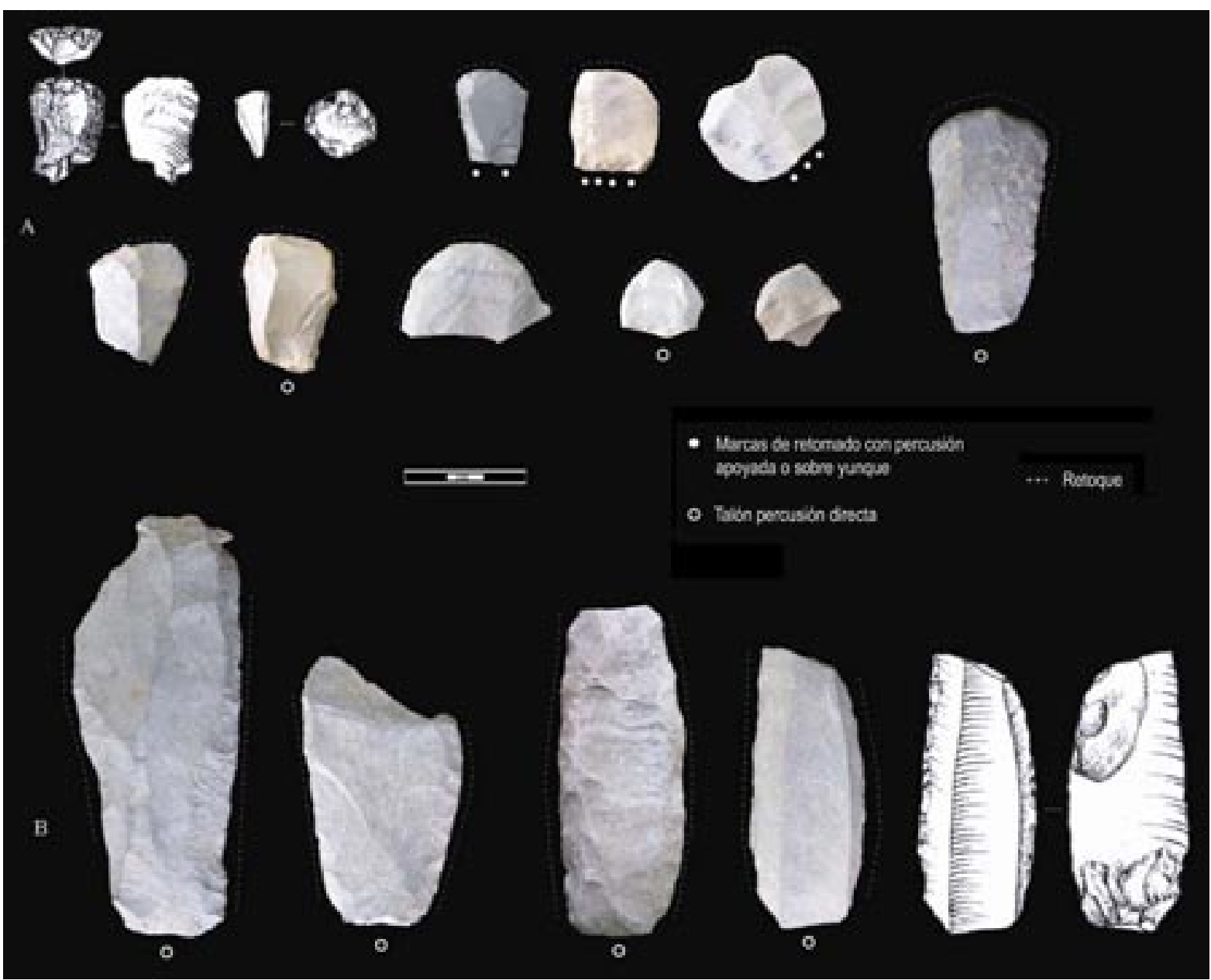

Fig. 8. Raspadores (A) y cuchillos (B) de Cerro Castillo (fotografías M. Langlais, dibujos D. Molez). 


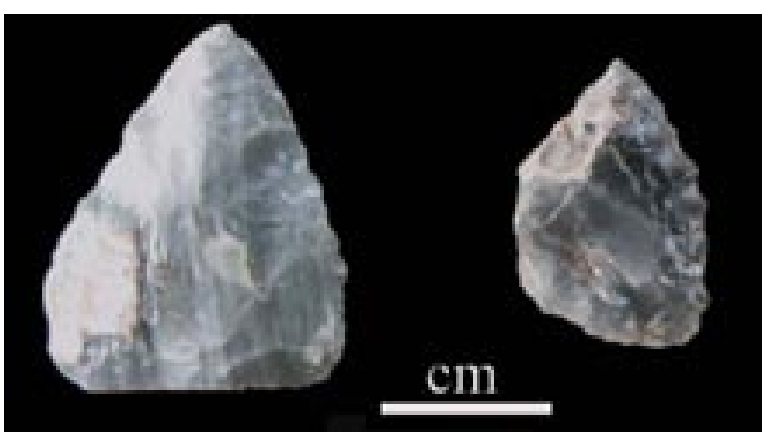

Fig. 9. Puntas de proyectil bifaciales en obsidiana gris veteada (Unidad Sedimentaria IV).

consideraron algunas piezas de filos vivos, a manera de hipótesis.
Se registra, igualmente, una diferencia económica en los cuchillos con relación a la gestión de las raederas. Los cuchillos presentan menos reavivado de filos y no se observaron procedimientos técnicos recurrentes de manutención. Esto podría explicarse por una menor intensidad de uso de estos instrumentos, aspecto que ameritaría un estudio detallado de traceología.

Otros Instrumentos

Otros artefactos retocados o formatizados pueden ser reagrupados en instrumentos laterales (entre los que están algunas piezas bifaciales) o de extremidad, por una parte, y los macro instrumen-

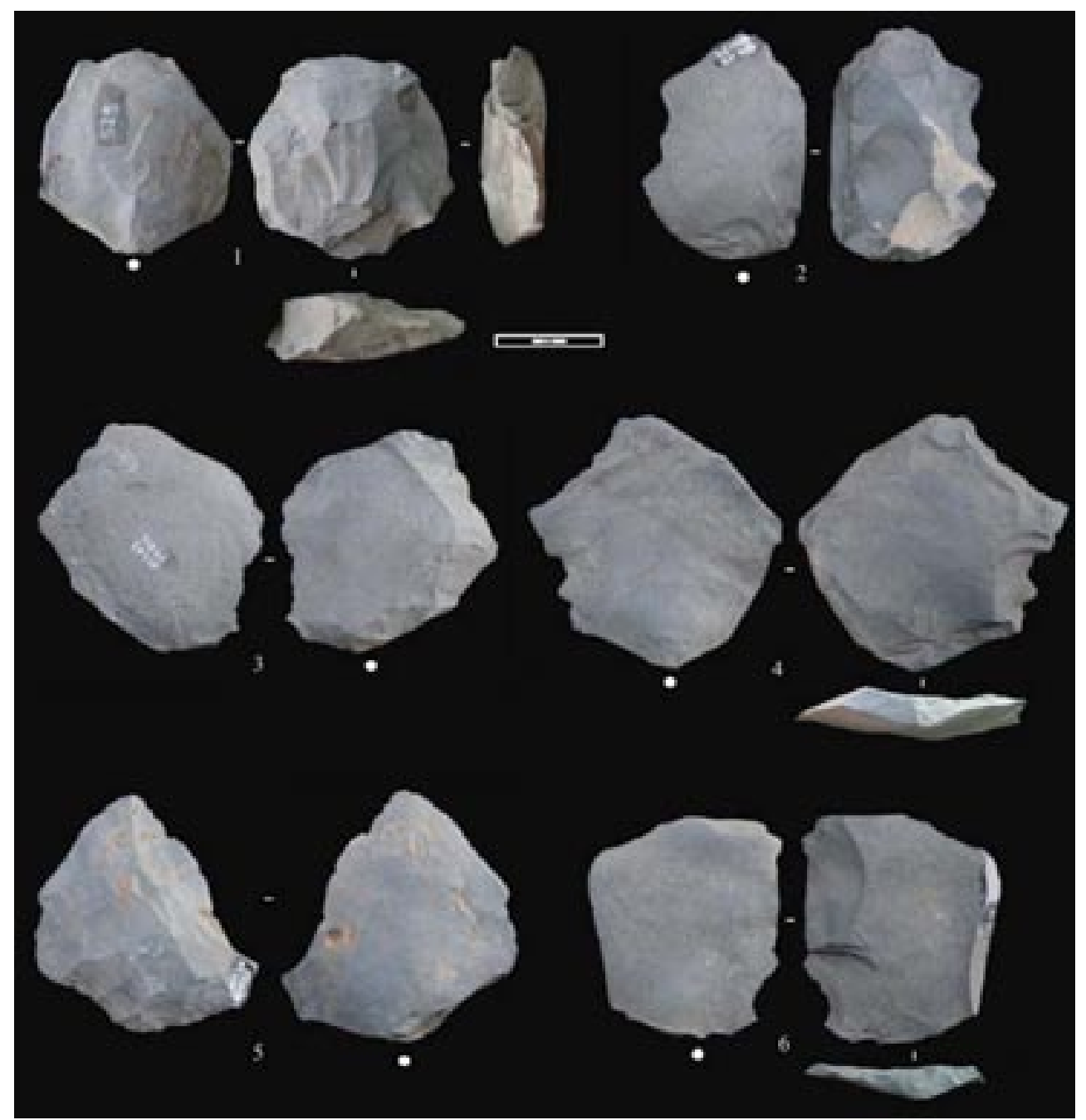

Fig. 10. Ejemplo de lascas invasivas o extendidas (envahissants), método Levallois (fotografías M. Langlais). 
tos, por otra. Entre los instrumentos laterales, ya evocamos el problema de ciertos artefactos bifaciales indeterminados.

Primero, es claro el caso de la gran bifaz de lutita silicificada (Fig. 3, dimensiones 142 × 71 × 12 $\mathrm{mm})$, que ha sido elaborada con percusión blanda. La presencia de varias lascas de façonnage del mismo material parece indicar que una parte de la formatización bifacial del artefacto fue realizada in situ en el yacimiento.

Otras piezas bifaciales se distinguen por su falta de simetría y regularidad, en comparación con la precedente (Fig. 4). Una de estas presenta un extremo astillado y triturado, localizado en el sector opuesto a un estigma de extracción sobre yunque (Fig.4 № 3). Estas marcas podrían indicar que esta pieza fue, ya sea, utilizada como cuña o desbastada al final de su curso utilizando esta técnica bipolar de percusión apoyada. En fin, entre estas otras piezas bifaciales indeterminadas hay dos casos que podrían integrarse en una variante del desbaste de lascas secantes, y entonces tendrían que considerarse como núcleos (Fig. 3 № 4).

Además, dos puntas bifaciales en obsidiana gris veteada, de forma sub-triangular y de pequeña dimensión (17 × 12 × 3 mm y 22 × 18 × 5 mm), provienen de la unidad estratigráfica IV (Fig. 9). Una tercera preforma de punta proviene de la unidad sedimentaria II y fue manufacturada en otra roca. En estas tres piezas, la formatización se realizó mediante presión.

\section{DESBASTE}

Luego de ahondar en los artefactos formatizados como instrumentos pasaremos a detallar, primero, los métodos de desbaste. Posteriormente se presentarán los datos de formatización de masas centrales bifaciales (façonnage), siendo éste un método de importancia secundaria en la serie, debido a su baja frecuencia.

A través del examen de los núcleos y fragmentos de núcleos $(\mathrm{N}=24)$, así como soportes brutos y retocados, se han reconstruido algunos de los comportamientos técnicos de los grupos de cazadores que ocuparon el alero Cerro Castillo. Se identificaron varias cadenas operatorias de producción de soportes para instrumentos. El examen de la distribución estratigráfica de los vestigios no
Tabla 4. Tipos de núcleo según materia prima y unidad sedimentaria (US).

\begin{tabular}{|c|c|c|c|c|}
\hline Núcleo / Mt.Prima & Lutita & Riolita & indet. & Total \\
\hline \multicolumn{5}{|c|}{ US II } \\
\hline discoidal centrípeto & 1 & & & 1 \\
\hline poliédrico & 1 & & & 1 \\
\hline Sub-Total & 2 & 0 & 0 & 2 \\
\hline \multicolumn{5}{|c|}{ US III } \\
\hline fragmentos & 3 & & 1 & 4 \\
\hline discoidal centrípeto & 3 & 1 & & 4 \\
\hline "Levallois" & 1 & & & 1 \\
\hline unipolar & 1 & & & 1 \\
\hline Sub-Total & 8 & 1 & 1 & 10 \\
\hline \multicolumn{5}{|c|}{ US IV } \\
\hline discoidal centrípeto & 4 & 2 & 1 & 7 \\
\hline fragmentos & 1 & 1 & & 2 \\
\hline poliédrico & 1 & 1 & & 2 \\
\hline "Levallois" & 1 & & & 1 \\
\hline Sub-Total & 7 & 4 & 1 & 12 \\
\hline US V & 0 & 0 & 0 & 0 \\
\hline Total & 17 & 5 & 2 & 24 \\
\hline
\end{tabular}

permite observar quiebres tecnológicos entre las unidades estratigráficas, por lo que se presentan como un conjunto. Desde el punto de vista terminológico, seguimos los preceptos definidos por análisis tecnológicos realizados recientemente sobre sitios de cazadores marítimos o terrestres, en el marco de una perspectiva analítica similar a la de nuestro estudio (Pigeot y Schidlowsky 1997; Schidlowsky 2001, 2003; Pigeot 2003; Morello 2005).

La mayoría de los núcleos y soportes fueron realizados en lutita y riolita (Tabla 4 ). Debido a la fuerte reducción de los núcleos, abandonados en un avanzado estado de agotamiento en la mayoría de los casos, y la frecuente recuperación de estas piezas con técnicas de percusión apoyada -sobre yunque-, hemos examinado de manera más detallada los grandes soportes brutos y retocados, con el fin de obtener información de las primeras secuencias de desbaste y evaluar la existencia de un continuo en la secuencia de extracciones, siguiendo una reducción lineal del volumen. De esta manera será posible distinguir conceptos volumétricos autónomos y diferentes modalidades operatorias que emanan del mismo esquema o plan conceptual (cf. Pigeot 2003, p. 130). Sin embargo, primeramente, describiremos las diferentes modalidades reconocidas antes de interrogarnos sobre la existencia de uno o varios esquemas conceptuales. 


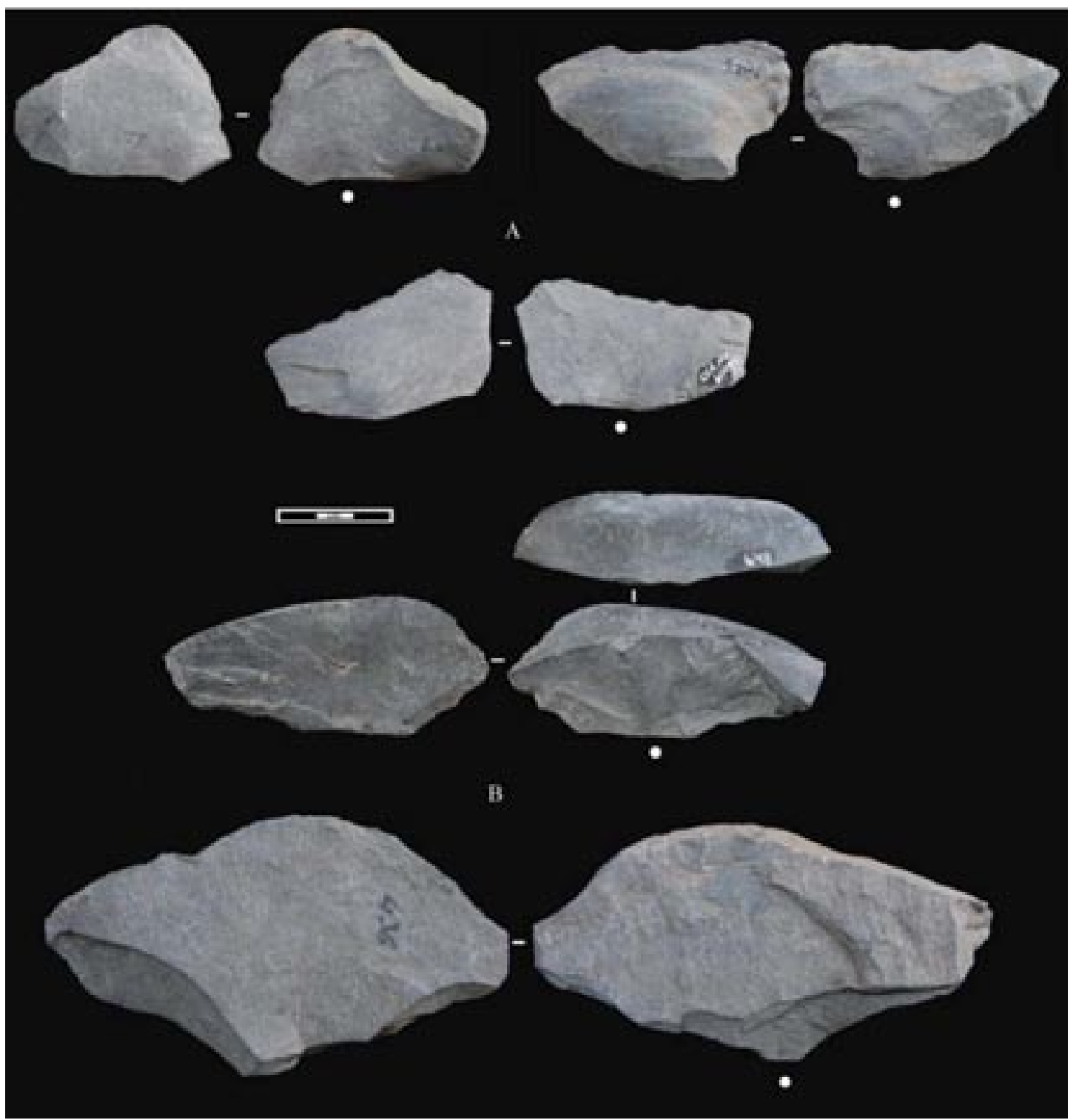

Fig.11. Muestra de lascas cortas unipolares (A) y de soportes desbastados sobre yunque (B) (fotografías M. Langlais).

Se identificaron varias modalidades operatorias que son testigo de la realización de diferentes tipos de soportes:

- Esquema de familia "Levallois": grandes productos, más o menos invasivos o extendidos (Fig. 10), y soportes de dorso natural, según una estructura de volumen del núcleo con dos caras y, en este sentido, se caracteriza como bifacial;

- Esquema de tipo "Discoidal": productos cortos y secantes, con negativos centrípetos, según una estructura también bifacial del volumen;
- Lascas extraídas de masas centrales (cf. Schidlowsky 2001), desbastadas o de façonnage;

- Esquema unipolar simplificado: soportes cortos, con una estructura unifacial del volumen del núcleo (Fig.11);

- Soportes alargados y, más bien, estrechos, según un esquema de tipo laminar;

- Soportes espesos de talón cortical, siguiendo un esquema de percusión sobre yunque (Fig.11);

- Otras pequeñas lascas según un esquema sobre yunque. 


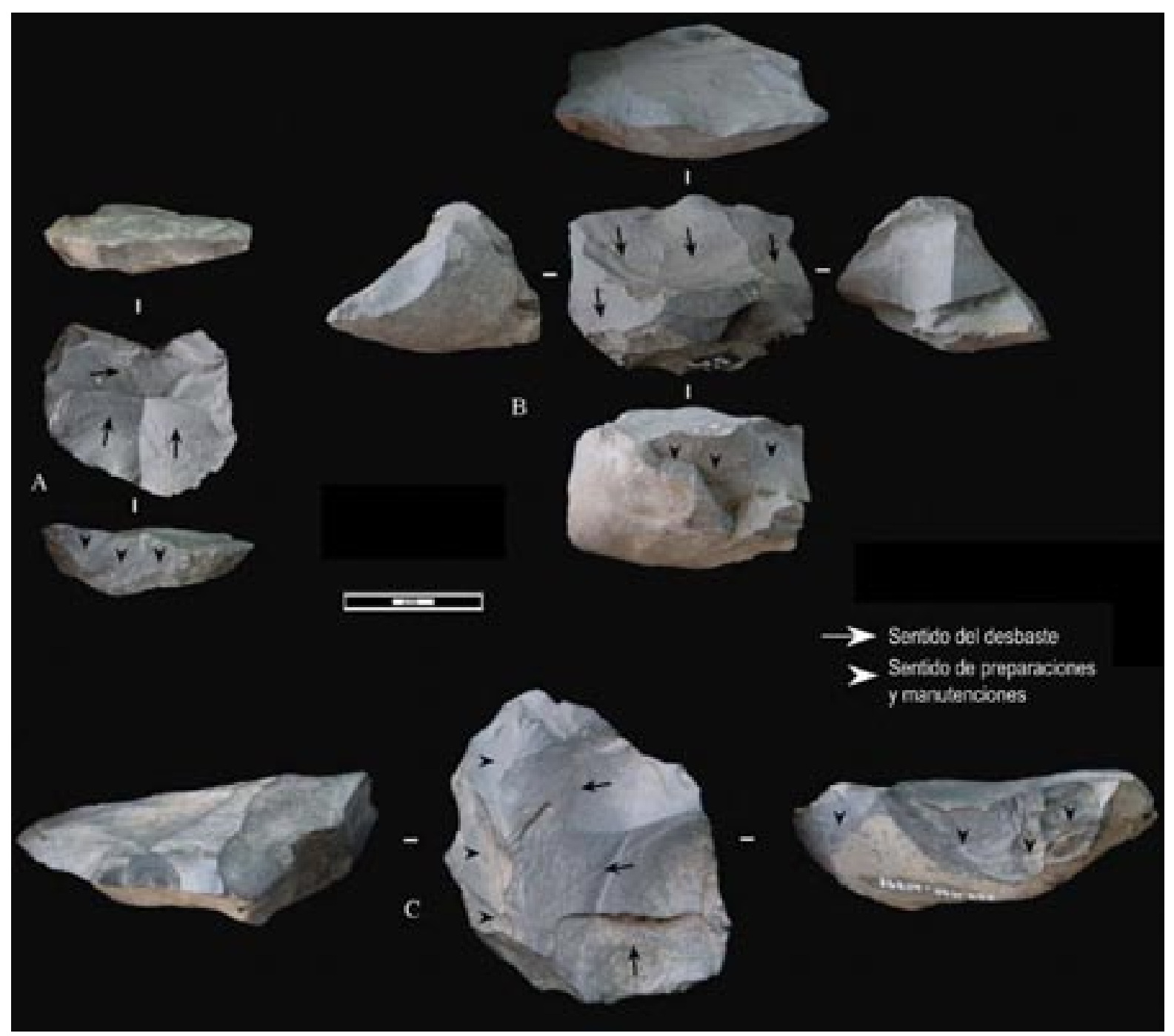

Fig. 12. Ejemplos de núcleos de lasca de estructura bifacial, tipos Levallois (A, en US III y C, en US IV) y Discoidal (B, US IV) (fotografías M. Langlais).

Desbaste en base a estructuras volumétricas bifaciales

\section{Levallois}

La presencia de grandes lascas, de negativos unipolares, transversales $e$ incluso centrípetos, y que presentan frecuentemente talones faceteados (Fig.10 № 4, 6), asociadas con lascas de dorso natural (Fig.10 № 1,3,6) que presentan negativos de acondicionamiento o formatización (predeterminantes) de las convexidades laterales, nos condujo a la hipótesis de un desbaste que podía integrarse al concepto Levallois. No volveremos sobre la definición de este concepto del Paleolítico europeo (Bordes 1961; Boëda 1986, 1994; Pigeot 1991) ni sobre su diagnóstico en contextos patagónicos (Nami 1992; Pigeot 2003; Morello 2005). Simplemente recordaremos que se trata de un desbaste de tipo facial, en un volumen de núcleo de conformación más bien bifacial; una cara que hace las veces de plano de desbaste y la otra de plataforma de percusión (Fig. 12 A y C).

En este tipo de desbaste la búsqueda de lascas expandidas, extensivas o invasoras (cf. Pigeot, 2003) requiere el acondicionamiento y manutención de 


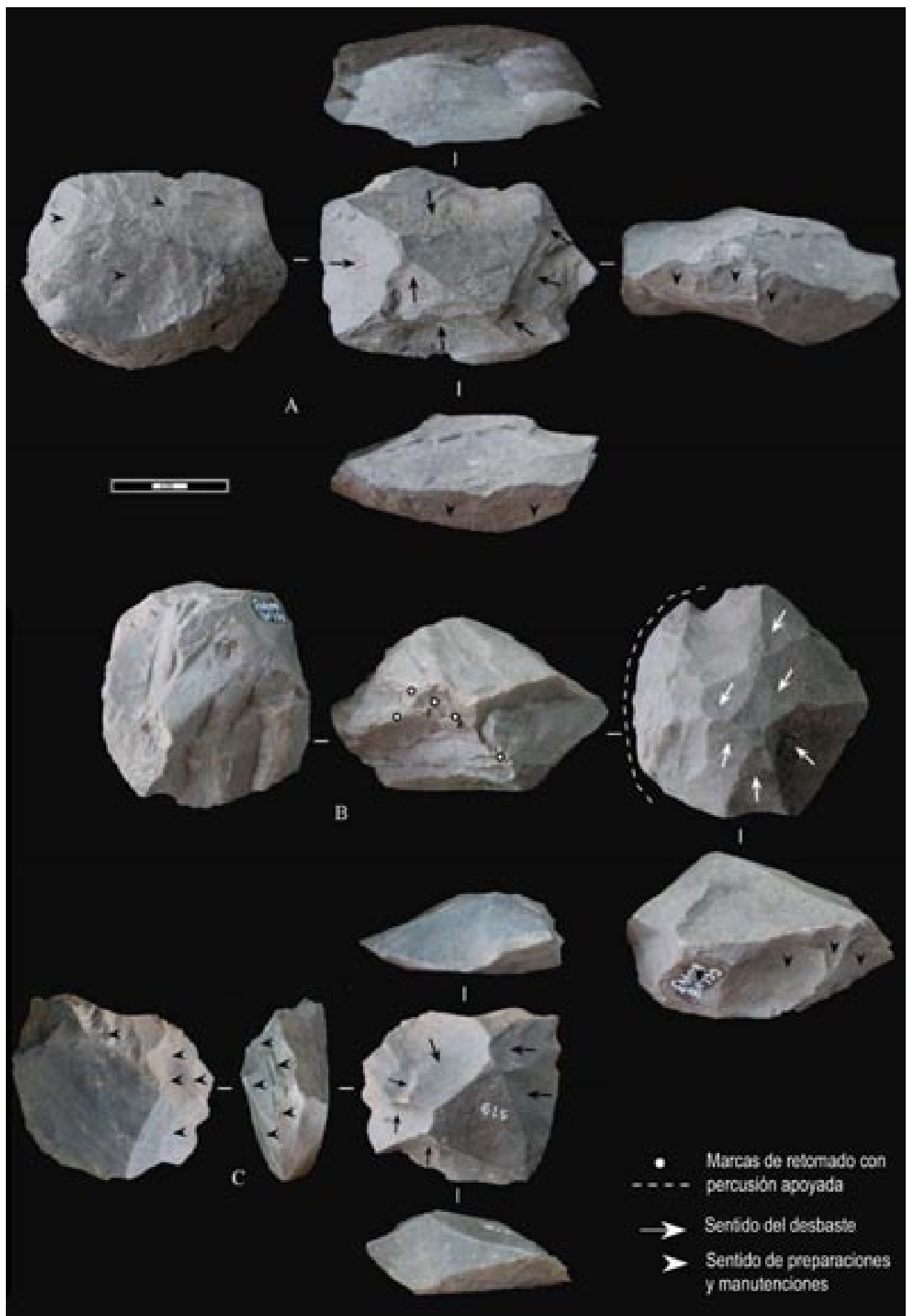

Fig. 13. Algunos núcleos de lasca de tipo Discoidal (fotografías M. Langlais). 
convexidades en ambas caras del núcleo, las que se materializan a través de extracciones cortas (secantes) de corrección distal o lateral sobre la cara de desbaste, y\o laterales sobre la cara correspondiente a la plataforma de percusión. Para esta formatización del volumen del núcleo también se usaron extracciones de lascas laterales desbordantes, las que se llevaron una parte de la plataforma de percusión al extraerse. Entre estas lascas desbordantes hay dos piezas con un retoque marginal rasante, opuesto al dorso natural (punto de desborde lateral). Otro caso de soporte de tipo laminar, utilizado como cuchillo, también parece corresponder a una extracción desbordante. Entre los productos de este método de desbaste, las lascas extendidas o Levallois, no desbordantes o poco desbordantes, las piezas de poco espesor $(<5 \mathrm{~mm})$ se registran generalmente en bruto, mientras que las lascas más espesas ( $>10$ $\mathrm{mm})$ son transformadas en raederas. Los núcleos son de guijarros morénicos como lo demuestra la frecuente corteza residual presente sobre la cara utilizada como plataforma de percusión.

\section{Discoidal}

Varios núcleos (Fig.12 B, Fig. 13) son testigo de un desbaste basado en una estructura volumétrica bifacial, realizado a partir de guijarros o de lascas espesas y siguiendo planos secantes y de recurrencia centrípeta. Se trata de núcleos y lascas que pueden ser integrados a la familia "Discoidal" (cf. Pigeot 1991; Boëda 1993; Schidlowsky 2001; Pigeot 2003). Como el caso precedente, el desbaste discoidal se organiza alrededor de dos superficies jerarquizadas en una estructura bifacial. La cara que hace las veces de plataforma de percusión es frecuentemente cortical, en cambio, la cara de desbaste presenta una sección de forma sub-triangular (Fig. 13). Las lascas obtenidas a partir de este esquema de desbaste son cortas y fueron transformadas en piezas con retoques laterales, algunas pequeñas raederas y raspadores.

\section{Otros}

Entre los elementos ordenados tipológicamente como piezas bifaciales, al menos dos artefactos conducen a interrogarse sobre su efectiva motivación tecno-económica: ¿núcleos, preformas de instrumentos o instrumentos retomados como núcleos? Así, en comparación con la única "verdadera" bifaz (cf. Infra, Fig.3), el espesor de la masa escogida, el empleo de percutor duro y la ausencia de regularización de los contra bulbos llevan a considerar estos artefactos bifaciales como piezas descartadas o instrumentos abandonados en curso de fabricación (preformas), o como núcleos de estructura volumétrica bifacial. En el estado de nuestros trabajos, los contabilizamos como instrumentos, manteniendo un bemol que concierne a su posible estatus de núcleo bifacial.

\section{Desbaste de estructuras volumétricas prismáticas}

La colección incluye dos núcleos que presentan una explotación unifacial de tipo unipolar simplificada con tendencia prismática. Se trata de un pequeño guijarro de lutita y de un fragmento de riolita desbastado sobre yunque, luego explotado con el fin de producir lascas cortas con una baja recurrencia. En el primer caso el dorso es cortical y, en el segundo, constituido por el revés de un accidente de tipo " $\mathrm{Si}$ ret" (cf. Tixier et al. 1980). El aprovechamiento de las convexidades naturales se nota por la ausencia de extracciones de preparación.

La presencia de lascas alargadas y de algunas láminas hacen contemplar la existencia de un concepto laminar de desbaste. En términos de la tipología de las láminas, se trata principalmente de soportes centrales que presentan nervaduras sub-paralelas al eje de desbaste, indicando para dos ejemplares, por lo menos, una buena recurrencia unipolar (productos de tres negativos, Fig. 8B). Estos soportes, de perfil curvo a rectilíneo, se presentan retocados en cuchillos. Un fragmento proximal de lámina retocada, de sección triangular espesa (19 $\mathrm{mm}$ ) y un raspador en calcedonia sobre lámina semicortical presentan una neocresta marginal que es testimonio de un cierto cuidado en la formatización de la carena del núcleo y confirman la búsqueda planificada de piezas alargadas. Dejaremos de lado la lámina más grande (106 mm, Fig. 8B), porque presenta un faldón oblicuo desbordante y podría provenir de una extracción expansiva de tipo Levallois, aunque presenta estigmas de una percusión blanda - contrario a la característica percusión dura propia de este método. También notamos la presencia de una lámina semicortical, que porta el negativo de una lámina de inicialización cortical. En este caso, el desbaste inicial no necesitó la preparación de 


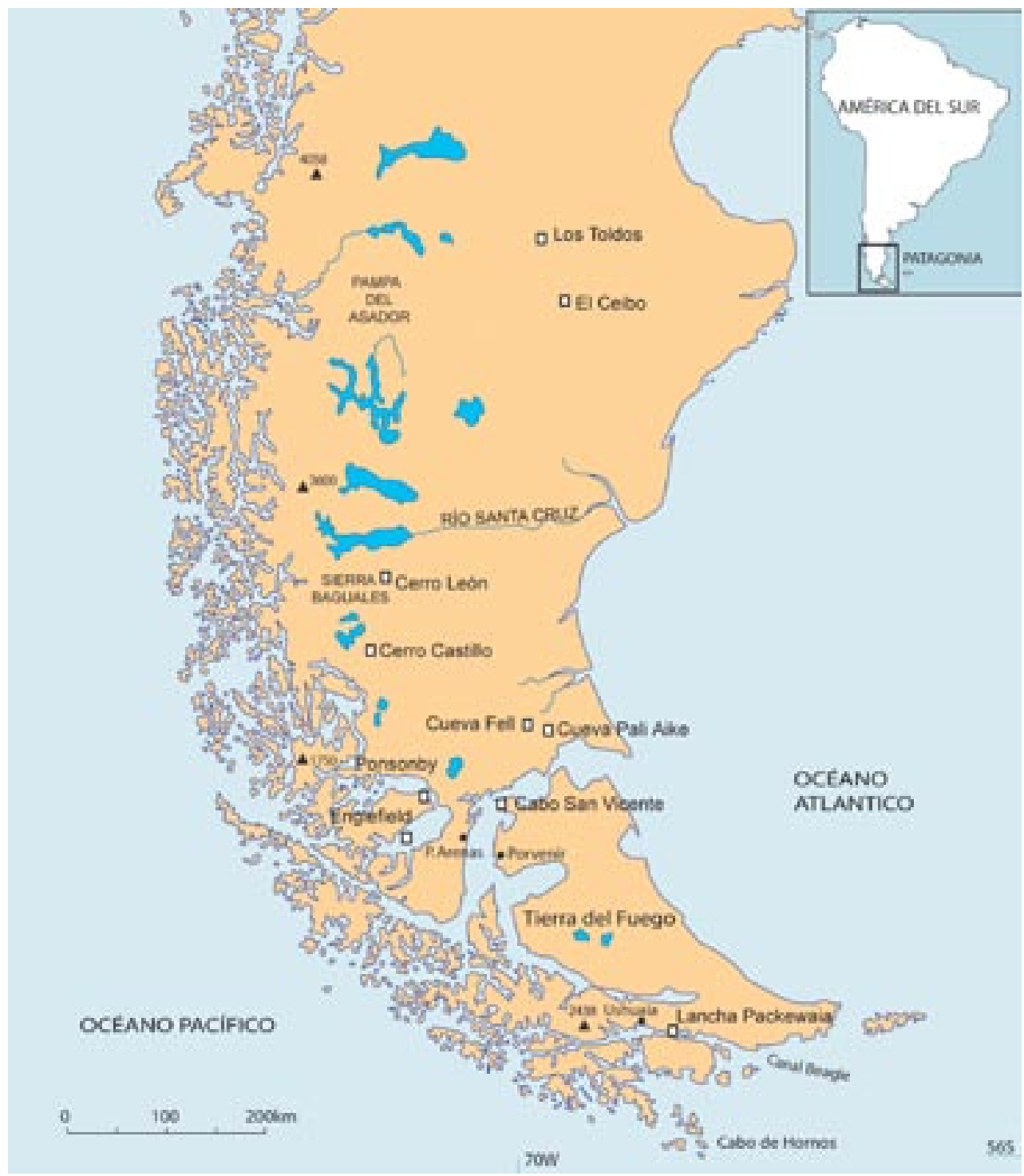

Fig. 14. Localización de algunos de los yacimientos arqueológicos mencionados en Fuego-Patagonia.

superficies transversales. La mayoría de las láminas presenta marcas de percusión blanda. En general, el número limitado de piezas no permite definir un esquema verdaderamente laminar (facial o prismático) sino que solamente adelantar la existencia de un concepto laminar autónomo que deviene un objetivo económico diferente a las lascas. No obstante, no hay evidencia que permita argumentar su producción en el sitio, siendo su importación, ya manufacturado, la posibilidad más factible, pero puede deberse también a un sesgo del muestreo, ya que el tamaño de la excavación fue reducido.
Desbaste sobre yunque: una opción de agotamiento del volumen

Esta técnica ha sido utilizada siguiendo varios objetivos como fracturar guijarros de lutita con el fin de conseguir soportes relativamente espesos, transformados en raspadores o raederas; desbastar pequeños guijarros de materias primas diversas con el objeto de obtener lascas pequeñas; y retomar núcleos de lasca de lutita y riolita, para producir algunos soportes al final de la vida útil del artefacto. 
El primer objetivo se identifica a través de marcas particulares en los talones de ciertas lascas $y$, particularmente, de raederas y raspadores. En otros casos, el núcleo residual es tipológicamente similar a las piezas esquillées (esquirladas) utilizadas como cuñas, también denominadas split ${ }^{2}$. Es factible que sea una técnica de fracturación que permitiría optimizar el desbaste de pequeños nódulos líticos, hasta su agotamiento. En fin, varios núcleos de lasca que han sido explotados según un esquema extendido o secante, presentan extremos con esquirlas incluso trituradas, así como algunos negativos de soportes extraídos por percusión sobre yunque.

En definitiva, la serie lítica de Cerro Castillo presenta una pluralidad de esquemas conceptuales que no parece emanar de una diferencia diacrónica, con relación a su distribución estratigráfica (cf. supra). Si dejamos de lado un proyecto laminar, que permanece marginal en el conjunto de la secuencia estratigráfica, y el desbaste de lascas con percusión sobre yunque, la arquitectura volumétrica de los núcleos es principalmente bifacial. Integra diferentes conceptos destinados a conseguir lascas expandidas y piezas de dorso natural (tipo Levallois) o lascas cortas y secantes (tipo Discoidal). Estos diferentes soportes se encuentran entre los instrumentos retocados, que analizaremos más tarde. La cuestión de la distinción y/o relación entre el concepto Levallois y Discoidal sigue siendo problemática (Pigeot 1991; Boëda 1993); la principal diferencia es una nueva mirada basada en las grandes caras del núcleo (Pigeot 1991:182). En el conjunto, aunque se trate de intenciones económicas diferentes, la consecución de las cadenas operativas desde una reducción de esquema de tipo "Levallois" hacia el "Discoidal" constituye una hipótesis de trabajo que merecerá ser considerada en nuevas series, como ha sido propuesto, por ejemplo, en Tierra del Fuego (Morello 2005).

\section{Percutores y talones}

El examen de los talones $(\mathrm{N}=540)$ permite caracterizar diferentes tipos de preparación para el desbaste y una diversidad de técnicas de aplicación de la fuerza. En cuanto a la percusión directa, la inmensa mayoría de los soportes fueron realizados

\footnotetext{
2 Pequeños núcleos generalmente llamados bipolares.
}

con percutor duro (67\%) siguiendo un gesto entrante, ejecutado por detrás de la cornisa. Por otra parte, las láminas y otros soportes alargados presentan rasgos diagnósticos (21\%) de una percusión blanda tangencial. Además, en muchas piezas la percusión es indeterminada. En comparación con los talones fracturados e indeterminados (12\%), lo esencial de las lascas, las lascas alargadas y láminas, tienen un talón liso $(\mathrm{N}=135)$ o facetado $(\mathrm{N}=103)$ y, en algunos casos (sobre todo lascas brutas), son diedros $(\mathrm{N}=66)$ o corticales $(\mathrm{N}=50)$. Por otro lado, vimos que ciertos soportes, particularmente raspadores y algunas raederas, han sido desbastados con percusión apoyada sobre yunque.

Con relación al façonnage, dos técnicas fueron utilizadas. La percusión directa blanda fue utilizada para formatizar masas de lutita, sílex o riolita. Por otra parte, un façonnage de puntas bifaciales en obsidiana gris veteada fue realizado a presión. En términos de tendencias, podemos sintetizar estos resultados de la siguiente manera:

- Un desbaste de lascas gestionado con percusión dura;

- Desbaste de láminas, preferentemente efectuado por percusión blanda;

- El desbaste de lascas efectuado por percusión apoyada sobre yunque;

- Façonnage de masas centrales con percutor blando;

- Façonnage de masas en obsidiana a presión.

\section{DISCUSIÓN}

A pesar de la escasa superficie excavada, la gran densidad de materiales permite caracterizar ciertos comportamientos tecno-económicos de los cazadores terrestres que ocuparon el alero Cerro Castillo, a través de su producción lítica. En primer lugar, una pluralidad de modalidades operatorias y económicas son testigos de una variedad técnica compuesta de varios esquemas conceptuales, más o menos representados en el conjunto. A estas se suma un proyecto laminar que se encuentra documentado sólo a través de los instrumentos registrados, cuchillos, raspadores y algunos soportes brutos. Aunque marginal en términos cuantitativos, el desbaste laminar está presente en el conjunto de la secuencia y no parece haber sido realizado en 
el yacimiento sino importado. El examen de colecciones de superficie que provienen de sitios al aire libre en la zona ${ }^{3}$ y que contienen núcleos de láminas en lutita, es un dato a considerar, y que merecerá ser analizado en profundidad en el futuro (Morello, F. com. pers).

Por otra parte, un procedimiento de percusión apoyada o sobre yunque ha sido utilizado como etapa final de algunas cadenas operatorias, con el fin de optimizar la rentabilidad de materiales de grano fino y módulos pequeños, y/o de núcleos de lasca retomados de lutita y riolita.

Lo esencial de la actividad de talla realizada in situ está consagrado a la producción de lascas como soporte de instrumentos retocados $y$, particularmente, de raederas. Para eso, una arquitectura volumétrica bifacial y, en menor grado, unifacial simplificada, ha sido integrada a diferentes esquemas conceptuales: una producción de lascas extendidas de tipo "Levallois" y un desbaste centrípeto de tipo "Discoidal". Este último parece ser ejecutado en las fases finales, a juzgar por el tamaño reducido de los módulos, y podría entonces corresponder a una continuidad en la reducción de los núcleos de volumen Levallois, acompañada por una simplificación de los gestos, lo que permite mejorar la rentabilidad del núcleo aumentando la recurrencia de extracciones centrípetas de lascas, en detrimento de las dimensiones de estos productos, al pasar a un tipo de desbaste discoidal.

Del punto de vista tecno-funcional, el lugar de las actividades cinegéticas permanece marginal, con sólo la presencia de dos puntas de proyectil en obsidiana gris veteada y a un probable alisador de astiles de flecha (San Román y Morello 2003). En este caso, suponemos que este tipo de actividades se desarrolló en otras áreas de la localidad. En el sitio Cerro Castillo, alrededor de los dos lentes de fogón, se concentra una buena parte de los materiales arqueológicos, y mayoritariamente las herramientas de transformación que dominan con el trío: raederas, raspadores, cuchillos. El cuidado tecno-económico dado a las raederas, la diversidad litológica de los raspadores y la presencia de cuchillos sobre láminas, llevan a

\footnotetext{
Musée du Quai Branly, Paris. Prospecciones de A. Laming-
} Emperaire en la Provincia de Última Esperanza, Chile. creer en una cierta duración de las ocupaciones del sitio y al desarrollo de actividades polivalentes. Pero, también se observa una manutención de las tradiciones culturales a lo largo de la secuencia, aunque queda por saber el intervalo del tiempo preciso, pues no se cuenta con dataciones de los niveles superiores del alero.

\section{Comparaciones Macro-Regionales}

A la vista de los estudios tecnológicos disponibles para industrias líticas, las comparaciones de los datos de Cerro Castillo se harán, principalmente, con respecto a yacimientos fechados y ampliamente excavados, y otros trabajos llevados a cabo en el marco de análisis tecnológicos similares que permiten ciertas equivalencias y comparación de la información.

La estratigrafía y periodificación de Cueva Fell sigue siendo una referencia básica para los cazadores terrestres de Patagonia austral (Bird 1993, Emperaire et al. 1963). A este título, se considera la datación del fogón 2 de Cerro Castillo, ca. 4.500 años AP, como situada en el inicio del período Magallanes IV, según la secuencia de Bird (1993). Este período particularmente se define a base de la presencia de grandes puntas de proyectil pedunculadas, ausentes del registro lítico de Cerro Castillo, pero también se caracteriza por el registro de pequeños raspadores de uña, el uso de grandes cepillos y perforadores pequeños y de talla bifacial (Massone 1981).

En esta misma época, pero en Patagonia norcentral, se desarrollaba el complejo denominado Casapedrense en las secuencias de los sitios Los Toldos y El Ceibo, entre otros, y con cronologías entre 7.000 y 4.000 años AP. Caracterizan este complejo la industria de láminas u hojas, con la presencia de núcleos prismáticos y piramidales. Las láminas son utilizadas principalmente para la manufactura de cuchillos y raspadores, e interesantemente carecían de puntas de proyectil pero sí de bolas para armas arrojadizas (Cardich 1977, Aguerre 1982, Crivelli 1981. En: Ottonello y Lorandi 1987).

Con relación a los cazadores recolectores marítimos, se hará referencia a los sitios de la cultura Englefield, que se desarrolló entre los 6.500 y 5.000 años AP (Legoupil y Fontugne 1997).

Por otra parte, estudios recientes han permitido mostrar una mayor complejidad del modelo de adaptaciones prehistóricas, particularmente a través 
del reconocimiento de conductas económicas de carácter mixto, en términos de subsistencia y dieta. Esto se ha documentado en el sitio de Ponsonby, isla Riesco (Legoupil 2003) y sería similar el caso de Lancha Packewaia, en Tierra del Fuego (Orquera et al. 1977) Estos dos yacimientos tienen fechas de ca. 4.500 años AP, para el Primer Componente de Lancha Packewaia y el nivel B de Ponsonby (op. cit.).

Comparaciones relacionadas con la distribución espacial de las materias primas, y considerando la presencia dominante de lutita o vulcanita, se recuerdan ciertos comportamientos observados entre grupos litorales de economía mixta, como Ponsonby y Lancha Packewaia (Pigeot 2003; Terradas 2003); en contraposición la obsidiana verde domina las series de la cultura marítima de Englefield, y el basalto es de mayor importancia entre los cazadores terrestres de Cueva Fell (Schidlowsky 2001), por ejemplo. Probablemente estas tendencias generales tienen relación con el acceso a las fuentes de aprovisionamiento respectivo.

En relación a las materias primas alóctonas, la obsidiana negra tiene su fuente ubicada en Pampa del Asador (Stern 2004), y la variedad gris veteada, de procedencia desconocida, pero probablemente cercana a Cerro Castillo, debería ubicarse cerca de la Cordillera Baguales (Stern y Franco 1992). Ambas obsidianas, junto con la excepcional calidad clástica de la obsidiana verde (también de fuente desconocida pero probablemente ubicada cerca de mar de Otway e isla Riesco, Morello et al. 2004), sirven para documentar el intercambio de materias primas y la interacción de grupos sobre grandes distancias. Además, permiten situar el sitio Cerro Castillo en redes de circulación mayores (supraregionales). En el caso de la obsidiana negra y verde, estos materiales permiten, también, establecer grados de compromiso económico, alrededor de factores como distancia a la fuente, calidad de la materia prima y morfometría de los nódulos potenciales. En Cerro Castillo, la abundancia en el medio ambiente inmediato de lutita, más o menos silicificada (incluida como RGFO en otros trabajos, por ejemplo, Borrazo 2008), y en bloques de grandes dimensiones, permitió que se ejecutara la mayoría de las cadenas operatorias de desbaste; aprovisionamiento que fue completado con un aporte menor de riolita y de una diversidad de rocas de calidades variables y que representan módulos de dimensión bastante más reducida.
Con relación a la esfera cinegética, ya hemos destacado que la excavación de Cerro Castillo indica la presencia muy marginal de la manufactura a presión de pequeñas puntas de proyectil sub-triangulares en obsidiana gris veteada. No obstante, queda la duda, primero, sobre su función como puntas de proyectil; segundo, sobre la etapa de su cadena operatoria en la que son abandonadas, permitiendo cuestionarse si se trata de preformas desechadas por errores de formatización o instrumentos modificados por su intenso reavivado o incluso retomados. A pesar de su escaso número, ciertas diferencias y semejanzas, en términos de dimensiones y morfología, pueden ser subrayadas con relación a otros conjuntos:

- Numerosas puntas bifaciales de tendencia más alargada en obsidiana verde fueron descritas para la Cultura Englefield, aunque estas fueron realizadas con percusión blanda y presión (Legoupil y Fontugne 1997, Schidlowsky 1997).

- Las puntas triangulares y sub-triangulares del período Fell o Magallanes III (Bird 1993) y puntas pedunculadas (Fell IV) son de dimensiones mayores, pero la morfología de las triangulares es similar. También eran manufacturadas con percusión blanda y presión;

- Las grandes puntas subfoliáceas de Ponsonby y Lancha Packewaia son morfométricamente muy distintas a las registradas en Cerro Castillo. Fueron realizadas a la percusión dura, luego blanda y, a veces, denticuladas con presión.

- La ausencia de puntas de proyectil para el Casapedrense es interesante de considerar, especialmente por su representación marginal en Cerro Castillo y la posibilidad de que no se trate de puntas de arma sino de otro instrumento o de preformas (sólo estudios de traceología podrían avanzar en esta cuestión).

En fin, en cuanto a las puntas de proyectil las semejanzas tipológicas se restringen a algunos ejemplares más pequeños de forma sublosángica o subtriangular de Cueva Fell (cf. Fig.164, En: Schidlowsky 2001), aunque las puntas subtriangulares de Cerro Castillo son más cortas y sin hombros basales, en el caso de que fueran consideradas instrumentos terminados y no preformas.

En relación a la esfera doméstica, la producción de soportes y la confección de instrumentos, abundantemente representada en Cerro Castillo, permiten interrogarse sobre los diferentes com- 
portamientos tecno-económicos observados. Se distinguen cuatro ejes: la existencia de un proyecto laminar, los métodos de desbaste de lascas, la producción bipolar sobre yunque, y los instrumentos de transformación, como las raederas.

En Cueva Fell, los períodos III y IV no muestran gran diferencia tipológica y tecnológica en términos de materias primas y producción (Schidlowsky 2001). En Fell III, el desbaste de lascas (predominantemente en basalto y riolita) se organiza según una estructura volumétrica bifacial (concepto discoidal de recurrencia centrípeta) o unifacial (op. cit.). Entre los instrumentos, las raederas de "retoque extendido" representan un tipo particular, caracterizado por extracciones semi-extendidas a invasivas que cubren, unifacial o bifacialmente la pieza, y que son anteriores al retoque de los bordes activos (op. cit., p. 217). Además, se documenta un proyecto laminar por medio de la presencia de cuchillos y un raspador sobre láminas en lutita, calcedonia y riolita. Los objetivos económicos se distinguen bien en términos de los soportes (espesos para las raederas, cortos para los raspadores y alargados para los cuchillos - Ibid.). Estas características acercan bastante estos conjuntos de Patagonia austral (Fell y Pali Aike) con lo descrito para Cerro Castillo, con la gran excepción de la importante presencia de façonnage bifacial en los primeros (puntas de proyectil Bird III y IV). Esta relación es extrapolable a diversos conjuntos líticos registrados en la Provincia de Santa Cruz, Argentina, agregándose que se ha registrado desbaste de tipo Levallois en la margen sur de Lago Argentino, en contextos de abrigos rocosos como Chorrillo Malo 2 y Cerro Verlika 1, $y$ al aire libre en Laguna Nimez, con dataciones entre ca. 3.800 y 1.800 años AP (Franco 2008). Estas lascas de formas predeterminadas son utilizadas para confeccionar raederas y cuchillos, sobre materias primas localmente disponibles. Además en el curso superior y medio del río Santa Cruz se ha observado la preparación de núcleos de hojas o láminas, aunque las dataciones asociadas son recientes (últimos 2000 años, op. cit).

En la zona sudeste de sierra Baguales (Provincia de Santa Cruz, Argentina), en localidades cercanas a Cerro Castillo, también se ha encontrado conjuntos con algunos de estos elementos. En los sitios Cerro León 1 y 3, con fechados de ca. 4.300 años AP, se caracteriza una industria con predominio del uso de lo que nosotros denominamos lutita, y que en otros estudios es considerado como parte de las rocas RGFO. En el conjunto del Alero Cerro León 3 hay un registro importante de raederas manufacturadas sobre soportes Levallois, a partir de núcleos preparados (sensu Nami 1992, 1997), y de instrumentos sobre láminas, mayoritariamente cuchillos (Borrazo 2006, 2008). En la localidad de Cerro León, en sitios a cielo abierto de la zona, se ha observado completa la cadena operativa de producción de estas láminas, también sobre la materia prima RGFO (lutita). Las relaciones con lo descrito para Cerro Castillo son evidentes, indicando relaciones culturales y contemporaneidad de los grupos que usaron estos espacios cercanos.

Con respecto al complejo Casapedrense, definido a partir de sitios de más al norte, destaca las semejanzas observadas en cuanto a ausencia de puntas de proyectil y en el proyecto laminar registrado en Cerro Castillo, tanto a nivel morfo-tecnológico como respecto a la formatización de estos soportes por retoque marginal preferentemente en cuchillos y raspadores (Cardich 1977, Crivelli 1981. En: Ottonello y Lorandi 1987).

Para el sitio de Ponsonby se describieron dos familias conceptuales de desbaste (principalmente sobre lutita y riolita): uno denominado Levallois simplificado y otro Discoidal (Pigeot 2003). Estos dos conceptos integran diferentes modalidades de producción basados en núcleos de volúmenes bifaciales. También se registra la presencia de escasos núcleos de tipo prismático, que muestran un desbaste envolvente, pero no se observa ningún proyecto verdaderamente laminar (Ibid.). En cuanto a los instrumentos, se trata de algunas raederas bastante elaborados y de raspadores unguiformes. En el seno de los primeros, se distinguen las piezas de retoque agudo, con una incidencia oblicua a rasante, y otros a retoque más abrupto; acercándose unos a una identificación como cuchillos y los otros a raederas (Pigeot 2003, p.148; Schidlowsky 2003). Es decir, más allá de similitudes generales, los procedimientos tecnológicos utilizados difieren de los observados en Cerro Castillo.

En Lancha Packewaia (Componente Antiguo), más de la mitad de la producción lítica se destina a la manufactura de puntas bifaciales (Orquera et. al. 1977; Schidlowsky 2006). Sobre el resto de las herramientas podemos anotar la ausencia de un 
proyecto laminar y una débil inversión en las materias primas (mayoritariamente riolita), con relación al façonnage, preferentemente realizado en vulcanita (Schidlowsky 2001). Se trata de un desbaste de lascas poco cuidado, a menudo reorientados según un esquema bifacial de tipo discoidal o unifacial (op. cit.). El equipo doméstico es poco abundante, representado por cuchillos y algunas raederas sobre lascas más bien finas. Entonces, el conjunto difiere notablemente de lo registrado en Cerro Castillo.

La cultura de Englefield se caracteriza por la explotación intensiva de la obsidiana verde como marcador cultural. Esta materia prima fue destinada a instrumentos y sobre todo al façonnage de puntas bifaciales bien pautadas (Legoupil 1997; Pigeot y Schidlowsky 1997; Schidlowsky 2001). Además, el sistema técnico está orientado por la búsqueda de la mayor longitud del filo, a partir del desbaste de plaquetas o láminas en obsidiana, pero también en lascas y bloques en otras rocas (Schidlowsky 2006). Un desbaste de tendencia laminar (Pigeot y Schidlowsky 1997) se realiza a partir de baguettes o plaquetas en obsidiana. Por otra parte, el desbaste de lascas fue utilizado a partir de una estructura volumétrica bifacial, con volúmenes definidos como "de eje" o "centrípeto" (Pigeot y Schidlowsky 1997; Schidlowsky 2001). Este último, el esquema bifacial centrípeto, corresponde a un concepto discoidal en el cual los roles de la plataforma de percusión y de superficie de desbaste, de las dos caras del núcleo, se invierten durante la explotación del bloque (Schidlowsky 2001, p.137). Los núcleos de este tipo presentan una variabilidad mayor entre otras rocas que no son la obsidiana, que, a la vez, presentan más cuidado en su ejecución. Por fin, un esquema llamado "facial transversal" (Pigeot y Schidlowsky 1997) también es utilizado. La hipótesis de un desbaste sobre yunque es propuesto para ciertas piezas. Las herramientas domésticas están compuestas por cuchillos, raspadores y puntas en obsidiana, pero igualmente por bifaces. Algunos cuchillos, raspadores y raederas están documentados en otras rocas (Schidlowsky 2001). En general, los puntos de semejanza tecno-económica con Cerro Castillo tienden a apoyan más una situación de contacto $e$ intercambio de materias primas que una relación cultural directa.

En fin, en conjuntos de recolección superficial, sin fechas asociadas y provenientes del norte de Tierra del Fuego se registraron, por una parte, la existencia de un proyecto laminar y por otra, la existencia del concepto Levallois (Morello, 2005, com. pers). Además, ciertas piezas de Cabo San Vicente registran la recuperación o retomado de núcleos de tipo Levallois en desbaste Discoidal y se documenta un tipo de desbaste en tajadas sobre yunque (op. cit.). Aunque la relación es muy compleja, por su lejanía espacial y su difuso marco cronológico, lo interesante es señalar la existencia de comportamientos tecno-económicos, en otras regiones de Fuego-Patagonia, que son equivalentes a una parte de las conductas registradas en el alero Cerro Castillo.

Así, excepto el façonnage, o formatización bifacial, que desempeña un papel marginal en la serie, el desbaste constituye la actividad de talla principal en Cerro Castillo. Diferentes objetivos económicos son realizados según una pluralidad cierta de modalidades operatorias. El proyecto laminar en lutita es diferente del realizado en obsidiana verde por parte de los grupos de la Cultura Englefield. Su presencia en Cueva Fell merecería comparaciones más profundas. Por otra parte, también hay que recordar que un proyecto laminar fue documentado en una serie de Cabo San Vicente, Tierra del Fuego. En Cerro Castillo, las láminas son destinadas a cuchillos y raspadores, y se asemejan en términos tecnológicos y morfológicos a las láminas retocadas del Casapedrense. El desbaste sobre yunque es puesto en ejecución sobre pequeños volúmenes en diversos materiales silíceos y jaspes, con el fin de producir lascas que son retocadas en raspadores a través de una percusión bipolar apoyada, también denominada split. Además, escasas lascas espesas de lutita retocadas en raederas, y algunos raspadores, también presentan las marcas características de esta técnica. Este procedimiento bastante simple se encuentra sin duda a Bahía Colorada (Schidlowsky 2001) pero igualmente en Cabo San Vicente, fue utilizado en el marco de un esquema operatorio reiterado, diferente a lo registrado en Cerro Castillo, cuyo objetivo era confeccionar raederas de tamaño grande a mediano (método en tajadas sobre yunque, Morello 2005).

Por último, la producción de lascas tiene un lugar principal en el sistema técnico de Cerro Castillo. Así, como a menudo en otros sitios de la región, este desbaste se organiza alrededor de 
una estructura bifacial del volumen del núcleo. El concepto discoidal se documenta en el conjunto de los yacimientos utilizados para la comparación, no apareciendo como un portador de carga cultural muy importante. Más bien parece depender de una búsqueda de rentabilidad en los soportes de bordes generalmente cortos, según una gestión relativamente simplificada de gestos técnicos. Por otra parte, la búsqueda de lascas extendidas que integran desechos de dorso natural (lascas desbordantes) es incluida en el seno del concepto Levallois, a partir de dos caras estrictamente jerarquizadas (plataforma de percusión y superficie de desbaste). Este concepto fue documentado en Ponsonby (Pigeot 2003) y en Tierra del Fuego (Nami 1992; Morello 2005) según diferentes modalidades. También se ha registrado en varios sitios en abrigos rocosos y al aire libre en el curso medio y superior del río Santa Cruz (Franco 2008) y cerca de Sierra Baguales (Borrazo 2006 , 2008), en localidades ubicadas inmediatamente al nororiente de Cerro Castillo. La presencia recurrente de este sistema de desbaste implica que estos grupos compartían ciertos conocimientos técnicos, aprendidos en un marco cultural de transmisión de información.

\section{CONCLUSIÓN}

Los resultados del estudio de la colección de Cerro Castillo tienden a demostrar el gran interés de este sitio para registrar de manera más fina la gestión del equipamiento lítico de estos grupos cazadores terrestres en Patagonia meridional. Este sitio contiene originalidades tecno-económicas que podrían, ya sea significar que estos grupos tienen tradiciones culturales débilmente orientadas hacia la manufactura o formatización bifacial (façonnage), o vincularse a cuestiones funcionales y/o sociales. Por otra parte, presenta similitudes a nivel de desbaste, en el sistema técnico basado en la gestión de volúmenes bifaciales destinados a producir lascas convertidas en raederas, que son, luego, cuidadosamente administradas. Otras cadenas operatorias, más marginales (proyecto laminar y desbaste sobre yunque), completan el sistema técnico.

Las comparaciones tipológicas y tecno-económicas indican una fuerte relación con los sitios de cronología similar y más tardía del río Santa Cruz, y de manera más difusa, se sugiere una relación con los momentos tardíos del período Fell III y el complejo Casapedrense. Además, la presencia de escasos restos de obsidiana negra y verde en el conjunto permiten situar a Cerro Castillo en las redes de circulación e intercambio supraregionales.

\section{AGRADECIMIENTOS}

El presente estudio fue financiado por el departamento de Cooperación Científica y Técnica del Ministère des Affaires Etrangères, Francia. Además, agradecemos al Proyecto ECOS-CONICYT CO4-HO1 "Caracterización de poblaciones de Cazadores-Recolectores terrestres y marítimos de Fuego-Patagonia en el curso del Holoceno", por su apoyo para el análisis de colecciones en Francia y Chile.

\section{BIBLIOGRAFÍA}

BERTRAN, P. 2009. Estudio geológico preliminar del alero rocoso de Cerro Castillo (Patagonia austral). Magallania 37(1).

BIRD, J. 1993. Viajes y Arqueología en Chile Austral. Ediciones de la Universidad de Magallanes., Punta Arenas, Chile.

BOËDA, E. 1986. Approche technologique du concept Levallois et évaluation de son champ d'application: étude de trois gisements saaliens y weichséliens de la France septentrionale. Thèse de Doctorat, Université de Paris $\mathrm{X}$, ex. multigraph, $385 \mathrm{p}$.

BOËDA, E. 1993. Le débitage Discoïde y le débitage Levallois récurrent centripète. BSPF, t.86, fasc. 6, p. 392-404.

BOËDA, E. 1994. Le concept Levallois: Variabilité des méthodes. Monographie du CRA n9, CNRS éditions, Paris.

BORDES, F. 1961. Typologie du Paléolítique ancien y moyen. Ed. Presses du CNRS (5e édition 1988)

BORRAZO, K. 2006. Tecnología lítica del Alero Cerro León 3 (Santa Cruz, Argentina). Magallania 34(2):63-74.

2008. Análisis tecnológico de distribuciones artefactuales en la periferia sudeste de la Sierra Baguales (Santa Cruz, Argentina). Magallania 36(1):103-116.

BOURGUIGNON, L. 1997 Le Moustérien de type Quina: nouvelle définition d'une entité technique. Thèse de Doctorat, Université de Paris X. 672 p.

- 1999. Analyse du processus opératoire des coups de tranchy s latéraux dans l'industrie de l'Abri du Musée (Les Eyziesdy ayac). Paléo 4:69-90. 
EMPERAIRE, J.; A. LAMING y H. REICHLEN. 1963. La Grotte Fell et autres sites de la region volcanique de la Patagonie Chilienne. Journal de la Société des Américanistes 52:167-229.

GENESTE, J.-M. 1985. Analyse lithique d'industries moustériennes du Périgord : une approche technologique du comportement des groupes humains au Paléolithique moyen. Thèse de Doctorat, Université de Bordeaux I. 572 p.

LEGOUPIL, D. (dir.) 1997. Bahia Colorada (île d'Englefield). Les premiers chasseurs de mammifères marins de $\mathrm{Pa}$ tagonie australe, Mémoire de l'APDF, Ed. Recherches sur les civilisations.

LEGOUPIL, D. (dir.) 2003. Les chasseurscueilleurs de Ponsonby (Patagonie australe) y leur environnement du VIe au IIIe millénaire av. JC., Magallania (Documentos), vol. 31.

LEGOUPIL, D. Y R. FONTUGNE. 1997. El Poblamiento marítimo en los archipiélagos de Patagonia: núcleos antiguos y dispersión reciente. Anales del Instituto de la Patagonia, Serie Ciencias Humanas 25:75-87.

LEGOUPIL, D. y BERTRAN, P. 2006. Les relations entre populations terrestres y maritimes de Patagonie, Labri Pedro Cardenas et l'abri Cerro Castillo, rapport de fouilles, $41 \mathrm{p}$.

LEGOUPIL, D. 2009. La Ocupación del Alero de Cerro Castillo en la antigua cuenca glaciar del Lago Toro hacia $V^{\circ}$ millenio AP. Magallania 37(1).

MASSONE, M. 1981. Arqueología de la Región de Pali-Aike (Patagonia Meridional Chilena). Anales del Instituto de la Patagonia 12:95-124.

MORELLO, F. 2005. Tecnología y métodos para el debaste de lascas en el norte de Tierra del Fuego: los nucleos del sitio Cabo San Vicente. Magallania 33:29-56.

MORELLO, F., M. SAN ROMÁN y A. PRIETO. 2004. Obsidiana verde en Fuego-Patagonia: distribución y estrategias tecnológicas. En Contra Viento y Marea. Arqueología de Patagonia, editado por P. F. y. A. G. G. M.T. Civalero, pp. 149-166. Edición del INAPL y la SAA, Buenos Aires.

NAMI, H. 1992. Noticia sobre la existencia de técnica "Levallois" en peninsula Mitre, extremo sudoriental de Tierra del Fuego. Anales del Instituto de la Patagonia, Serie Ciencias Humanas, 21:73-80.

- 1997. Más datos sobre la existencia de Nucleos preparados y lascas predeterminadas en la Patagonia Austral. Anales del Instituto de la Patagonia, Serie Ciencias Humanas 25:223-227.

ORQUERA, L. A., A.E. SALA, E. PIANA, y A.H. TAPIA. 1977. Lancha Packewaia. Arqueología de los Canales Fueguinos. Temas de Arqueología, Editorial Huemul S.A.
OTTONNELLO, M. Y A. M. LORANDI. 1987. Introducción a la Arqueología y Etnología. Diez mil años de Historia Argentina. EUDEBA, Buenos Aires.

PIGEOT, N. 1991. Réflexions sur l'histoire technique de l'homme : de l'évolution cognitive à l'évolution culturelle. Paléo $3: 167-200$.

PIGEOT, N. 2003. L'économie de la taille de la pierre. In: LEGOUPIL D. (dir.), Les chasseurscueilleurs de Ponsonby (Patagonie australe) et leur environnement du VIe au IIIe millénaire av. JC., Magallania (Documentos), vol. 31, p. 117-164.

PIGEOT, N. y SCHIDLOWSKY, V. 1997. L'équipement en pierre taillée sur "galy". In: LEGOUPIL, D. (dir.), Bahia Colorada (île d'Englefield). Les premiers chasseurs de mammifères marins de Patagonie australe, Mémoire de l'APDF, Ed. Recherches sur les civilisations, p. 129-135.

SAN ROMAN, M. y MORELLO, F. 2003. Nota sobre una excavación de sondeo en el alero Cerro Castillo 1. Provincia de Última Esperanza, Magallanes, Chile. Magallania 31:139-147.

SCHIDLOWSKY, V. 2001. Les premiers chasseurs maritimes y les chasseurs terrestres de Patagonie australe. Comportements technoéconomiques et identité culturelle, $B A R$ international serie ${ }^{\circ} 954$, Oxford.

SCHIDLOWSKY, V. 2003. L'outillage en pierre taillée: singularité des concepts y influences régionales. In: LEGOUPIL D. (dir.), Les chasseurscueilleurs de Ponsonby (Patagonie australe) et leur environnement du VIe au IIIe millénaire av. JC., Magallania (Documentos), vol. 31, p. 165-204.

SCHIDLOWSKY, V. 2006. Identité culturelle y technologie lítica: les comportements technoéconomiques des premiers chasseurs maritimes y des chasseurs terrestres de $\mathrm{Pa}$ tagonie australe. In: YACOBACCIO H.D. y OLIVERA D.E., Change in the Andes: origins of social complexity, Pastoralism and agriculture, section 17, Actes du XIVe congrès de l'IUSPP, Liège, 2001, BAR international serie $n^{\circ} 1524$, Oxford, p. 191201.

STERN, C. 2004. Obsidian in Southern Patagonia: review of the current information. En: Contra Viento y Marea. Arqueología de Patagonia, edited by P. Fernández y A.G. Guraieb M.T. Civalero. Edición del INAPL y la SAA, Buenos Aires.

TERRADAS, X. 2003. Caractérisation des matières premières líticas. En: LEGOUPIL D. (dir.), Les chasseurscueilleurs de Ponsonby (Patagonie australe) y leur environnement du VIe au IIIe millénaire av. JC., Magallania (Documentos), vol. 31, p. 419423. 
